\title{
SPILLOVER EFFECTS IN INTERNATIONAL BUSINESS CYCLES
}

\section{0}

\section{BANCODEESPAÑA}

Eurosistema

Documentos de Trabajo

N. ${ }^{\circ} 2034$

Máximo Camacho, Matías Pacce

and Gabriel Pérez-Quirós 
SPILLOVER EFFECTS IN INTERNATIONAL BUSINESS CYCLES ${ }^{(*)}$

Máximo Camacho ${ }^{(*)}$

UNIVERSITY OF MURCIA AND BBVA RESEARCH

Matías Pacce ${ }^{(* *)}$

BANCO DE ESPAÑA

Gabriel Pérez-Quirós

EUROPEAN CENTRAL BANK AND CEPR

${ }^{(*)}$ We are thankful to seminar participants at the Vrije Universiteit (VU) Amsterdam, Universidad de Alicante, and BBVA Research for their helpful discussions and comments. M. Camacho acknowledges the financial support from project ECO2016-76178-P (MCIU/AEI/FEDER/UE) and the program Groups of Excellence of the Region of Murcia, Fundación Séneca project 19884/GERM/15. All remaining errors are our responsibility. The views expressed in this paper are our own and do not necessarily reflect the views of the Banco de España or the European System of Central Banks (ESCB).

$\left(^{(*)}\right.$ Universidad de Murcia, Facultad de Economía y Empresa, Departamento de Métodos Cuantitativos para la Economía y la Empresa, 30100 Murcia, Spain. E-mail: mcamacho@um.es.

$\left.{ }^{* \star *}\right)$ Corresponding Author: Banco de España, Departamento de Análisis de la Situación Económica, 28014 Madrid, Spain. E-mail: matias.pacce@bde.es. 
The Working Paper Series seeks to disseminate original research in economics and finance. All papers have been anonymously refereed. By publishing these papers, the Banco de España aims to contribute to economic analysis and, in particular, to knowledge of the Spanish economy and its international environment.

The opinions and analyses in the Working Paper Series are the responsibility of the authors and, therefore, do not necessarily coincide with those of the Banco de España or the Eurosystem.

The Banco de España disseminates its main reports and most of its publications via the Internet at the following website: http://www.bde.es.

Reproduction for educational and non-commercial purposes is permitted provided that the source is acknowledged.

(C) BANCO DE ESPAÑA, Madrid, 2020

ISSN: 1579-8666 (on line) 


\section{Abstract}

To analyze the international transmission of business cycle fluctuations, we propose a new multilevel dynamic factor model with a block structure that (i) does not restrict the factors to being orthogonal and (ii) mixes data sampled at quarterly and monthly frequencies. By means of Monte Carlo simulations, we show the high performance of the model in computing inferences of the unobserved factors, accounting for the spillover effects, and estimating the model's parameters. We apply our proposal to data from the G7 economies by analyzing the responses of national factors to shocks in foreign factors and by quantifying the changes in national GDP expectations in response to unexpected positive changes in foreign GDPs. Although the share of the world factor as a source of the international transmission of fluctuations is still signicant, this is partially absorbed by the spillover transmissions. In addition, we document a pro-cyclical channel of international transmission of output growth expectations, with the US and UK being the countries that generate the greatest spillovers and Germany and Japan being the countries that generate the smallest spillovers. Therefore, policymakers should closely monitor the evolution of foreign business cycle expectations.

Keywords: international business cycles, mixed frequency data, bayesian estimation, spillover effects.

JEL classification: E32, C22, F42, F41. 


\section{Resumen}

Con el objetivo de analizar la transmisión de las fluctuaciones internacionales de los ciclos económicos, se propone un modelo de factores dinámicos multinivel con estructura de bloques en el que: i) no se restringe a los factores a ser ortogonales, y ii) se permite mezclar series de frecuencia mensual y trimestral. A través de simulaciones de Monte Carlo, se muestra la precisión en el cómputo de los factores no observados (teniendo en cuenta los efectos de transmisión) y en la estimación de los parámetros del modelo. El modelo propuesto se aplica a las economías del G-7. Por un lado, se analizan las respuestas de los factores nacionales a las perturbaciones originadas en los factores externos y, por otro, se cuantifica el cambio en la previsión de crecimiento del PIB nacional como consecuencia de incrementos inesperados en las previsiones de crecimiento del PIB del resto de los países. Si bien la proporción del factor global como fuente de transmisión de las fluctuaciones internacionales es significativa, esta es parcialmente absorbida por los efectos de transmisión. Además, se documenta un canal procíclico de la transmisión internacional de las expectativas de crecimiento del PIB, donde Estados Unidos y el Reino Unido son los países que producen el mayor efecto de derrame, y Alemania y Japón los que menores efectos de transmisión generan. Por todo ello, los responsables de políticas económicas debieran supervisar de cerca la evolución de las expectativas relacionadas con el desarrollo de los ciclos económicos externos.

Palabras clave: ciclos económicos internacionales, datos de frecuencia mixta, estimación bayesiana, efectos de derrame.

Códigos JEL: E32, C22, F42, F41. 


\section{Introduction}

Disentangling the contribution of internal and common external shocks to domestic output variability, together with the identification and quantification of spillover effects from foreign shocks to the domestic economy have been an important subject of research in recent years. Overall, the literature supports the finding that common and country-specific shocks exhibit a larger role in explaining business cycle fluctuations than spillover effects (Monfort et al., 2003; Stock and Watson, 2005; Dées and Vansteenkiste, 2007). In this context, the analysis of international co-movements across economies typically relies on two key assumptions.

First, the model framework is a dynamic factor model with block structures - also known as a multilevel dynamic factor model - as in Gregory et al. (1997), Kose et al. (2003), and Crucini et al. (2011), among others. These models assume that fluctuations in countries' aggregates are basically explained by a component common to all countries (interpreted as the international business cycle, IBC hereafter), by a country-specific component (the national business cycle), and by idiosyncratic dynamics specific to each variable. Although these models assume orthogonality between unobserved factors for identification reasons, Stock and Watson (2005) show that they fail to accurately identify responses to common shocks from spillover effects because all crosscountry dynamics are restricted to coming from the world component.

Second, the empirical applications rely on annual or quarterly databases, which agree with the data availability of Gross Domestic Product (GDP) as it is the most relevant measure of economic activity. However, this implies assuming that the international transmission of business cycle linkages applies only at the level of these large time periods, omitting from the analysis the valuable information of economic indicators that are sampled at higher frequencies. Thus, there is a potential need for dynamic factor models with block structures to combine data from different frequencies and to exploit the analysis of the international transmission of business cycle shocks at shorter frequencies. ${ }^{1}$

Aiming to handle both of the abovementioned concerns, we propose a new framework that deals with both mixed frequencies in dynamic factor models (MF-DFMs) and block structures where factors are not restricted to being orthogonal between each other. We deal with mixed frequencies by "stacking" quarterly and monthly economic indicators as in Blasques et al. (2016). In addition, we deal with spillover effects in multilevel dynamic factor models by allowing dependence across the factors as in Bai and Wang's (2015), who show that the factor orthogonality

\footnotetext{
${ }^{1}$ The benefits of enlarging a model to deal with mixed frequencies when analyzing the dynamic propagation of shocks has already been shown by Eraker et al. (2014) and Foroni and Marcellino (2016) in the context of vector autoregression (VAR) models. To the best of our knowledge, only Aruoba et al. (2011) allow for mixed frequencies to analyze international business cycles in a hierarchical factor model, which does not handle spillover effects.
} 
assumption is a sufficient but not necessary condition for identification purposes. Finally, we rely on Bayesian techniques to estimate the model's parameters as in Koopman and Pacce's (2016) by using a Metropolis-Hasting within Gibbs sampling algorithm. ${ }^{2}$

To evaluate the performance of our proposal, we conduct a set of Monte Carlo simulations whose data-generating processes are characterized by data sampled at quarterly and monthly frequencies and spillover effects. Our results suggest that adding quarterly variables in the estimation procedure always results in a gain in terms of estimation accuracy, as measured by the R-squared of regressing the estimated factor on the true ones. Nevertheless, we also find that these improvements diminish with the number of monthly variables that are included in the model. Our Monte Carlo results also illustrate the high performance of our methodology in capturing the spillover effects.

To illustrate our approach empirically, the multilevel MF-DFM is applied to estimate both the IBC and country-specific cycles at monthly frequencies from January, 1980 to December, 2018 for countries belonging to the G7. Apart from quarterly national GDP, we follow Stock and Watson (1989) and enlarge the set of indicators with industrial production, retail sales, employment, and household income (whenever available). Within this framework, we find the following notable results. First, the estimated factors are able to capture most of the major economic events occurring during the sample period. Second, the share of output variance explained by the common component is significant, albeit lower than that usually obtained in the IBC literature. We show that this result is directly related to the assumption of nonorthogonality across factors because a large portion of the dynamics explained by the world factor is translated to each of the country factors when spillovers are allowed.

Third, we measure the spillover effects in IBC dynamics by computing the impulse response functions (IRFs) of the global and each of the country-specific factors to shocks in the dynamics of the other factors. Our findings suggest a rapid transmission of the international shocks, regardless of whether the shock affects the common factor or the country-specific factors. In particular, shocks hitting the global factor lead to pro-cyclical country-specific reactions, which indicates a significant role of the world factor in the dynamics of each of the G7 economies. In addition, we find spillovers emerging from each of the domestic economies to foreign economies, the US being the only country that generates a positive effect in all other countries. These results are in line with Diebold and Yilmaz (2015), Antonakakis et al. (2016), and Carstensen and Salzmann (2017), who also find that international spillovers play an important role in national business cycles dynamics.

\footnotetext{
${ }^{2}$ An additional advantage of our proposal is that it allows for missing observations, meaning series of different lengths can be included.
} 
Fourth, we address the extent to which shocks to national GDP affect foreign GDP dynamics by conducting a conditional forecast analysis in line with Banbura et al. (2015). In particular, we compare two different conditional forecast scenarios. In the first scenario, we compute the GDP point forecasts $T+1$ for a given country, where $T$ is the last quarter of available GDP data. Conditional on this forecast, we also compute the forecasts from $T+1$ to $T+4$ for all of the G7 economies. In the second scenario, we start from the GDP point forecast $T+1$, but we add to it half a standard deviation and we compute a second set of conditional forecasts from $T+1$ to $T+4$ for all of the $\mathrm{G} 7$ economies. We interpret the cumulative difference between the two scenarios as the potential impact that an economic innovation in one particular country has on other economies.

As a result of these conditional forecast comparisons, we find that a positive innovation in the GDP of each of the G7 economies never results in a negative impact on the GDP growth of the other G7 partner countries. In addition, we find that the US and UK are the countries with larger positive effects on the other economies, whereas shocks to German and Japanese GDPs only have a small impact on the output of the other G7 countries.

The policy implications of our results are clear: given the relevance of the international transmission of business cycle effects that we find in this paper, stabilization policies aimed at reducing fluctuations and maintaining healthy levels of economic growth should also closely monitor the evolution of foreign business cycles.

The paper is organized as follows. Section 2 presents our multilevel mixed-frequency dynamic factor model. Section 3 discusses the estimation strategy. Section 4 provides the results of the Monte Carlo simulations. Section 5 describes the empirical application and presents the results. Section 6 offers some concluding remarks. Finally, the Appendix provides technical details and some additional results.

\section{Methodological framework}

\subsection{The model}

Multiple dynamic factor models with a block structure are the commonly used framework when different levels of co-movements are assumed among economic variables. For instance, Gregory et al. (1997), Kose et al. (2008), and Crucini et al. (2011) assumed a two-level structure in order to characterize the business cycle at an international and at a country level. The model presented in this paper is an extension of this kind of multilevel representation.

Let $\tau=1, \cdots, \mathcal{T}$ represent time periods; let $c=1, \ldots, C$ stand for countries; let $n_{c}$ be the number of variables for each country $c$; and let $N=\sum_{c=1}^{C} n_{c}$ be the total number of variables 
included in the model. The source of variation of any observable variable $\left(y_{\tau}^{i c}\right)$, with $i=1, \ldots, n_{c}$, is assumed to depend on a factor $F_{\tau}^{w}$ (the "world factor") common to all countries, on a groupspecific component $f_{\tau}^{c}$ (the "country factor"), and on the idiosyncratic dynamics of each variable $\left(u_{\tau}^{i c}\right){ }^{3}$ Therefore, the model can be specified as

$$
y_{\tau}^{i c}=\beta_{w}^{i c} F_{\tau}^{w}+\beta^{i c} f_{\tau}^{c}+u_{\tau}^{i c}
$$

where both $\beta_{w}^{i c}$ and $\beta^{i c}$ are the loading factors, capturing the sensitivity of each variable to the latent factors. As usual, $u_{\tau}^{i c}$ is assumed to be normally distributed and possibly serially correlated following a $p_{i c}$-order autoregression:

$$
u_{\tau}^{i c}=\phi_{1}^{i c} u_{\tau-1}^{i c}+\cdots+\phi_{p_{i c}}^{i c} u_{\tau-p_{i c}}^{i c}+\varepsilon_{\tau}^{i c}
$$

where

$$
E\left[\varepsilon_{\tau}^{i c} \varepsilon_{\tau-s}^{j k}\right]=\left\{\begin{array}{ll}
\sigma_{\varepsilon^{i c}}^{2} & \text { for } i=j, c=k \text { and } s=0 \\
0 & \text { otherwise }
\end{array} .\right.
$$

Putting all observable variables and innovations into two $N \times 1$ vectors $Y_{\tau}=\left[y_{\tau}^{11}, \ldots, y_{\tau}^{n_{1} 1}, \ldots, y_{\tau}^{1 C}\right.$, $\left.\ldots, y_{\tau}^{n_{C} C}\right]^{\prime}$ and $U_{\tau}=\left[u_{\tau}^{11}, \ldots, u_{\tau}^{n_{1} 1}, \ldots, u_{\tau}^{1 C}, \ldots, u_{\tau}^{n_{C} C}\right]^{\prime}$, equation (1) could be written in the following matrix form:

$$
Y_{\tau}=\left[\begin{array}{ll}
\mathbf{B}_{w} & \mathbf{B}_{c}
\end{array}\right] \mathbf{F}_{\tau}+U_{\tau}
$$

where $\mathbf{F}_{\tau}=\left[F_{\tau}^{w}, f_{\tau}^{1}, \ldots, f_{\tau}^{C}\right]^{\prime} ; \mathbf{B}_{w}=\left[\begin{array}{lll}B_{1}^{w \prime} & \ldots & B_{C}^{w \prime}\end{array}\right]^{\prime}$, with $B_{c}^{w}=\left[\beta_{w}^{i c}, \ldots, \beta_{w}^{n_{c}}\right]^{\prime} ;$ and $\mathbf{B}_{c}$ is a diagonal matrix with $\left[\begin{array}{lll}B_{1} & \cdots & B_{C}\end{array}\right]^{\prime}$ in the main diagonal, with $B_{c}=\left[\beta^{i c}, \ldots, \beta^{n_{c} c}\right]^{\prime}$. Regarding the unobserved component dynamics, the common assumption in the literature is that each factor could follow an independent autoregressive process of order $q$. Considering a $\operatorname{VAR}(1)$ specification, the process could be written as

$$
\left(\begin{array}{c}
F_{\tau}^{w} \\
f_{\tau}^{1} \\
\vdots \\
f_{\tau}^{C}
\end{array}\right)=\left(\begin{array}{cccc}
\phi_{w} & 0 & \ldots & 0 \\
0 & \phi_{1} & \ldots & 0 \\
\vdots & \vdots & \ddots & \vdots \\
0 & 0 & \ldots & \phi_{C}
\end{array}\right)\left(\begin{array}{c}
F_{\tau-1}^{w} \\
f_{\tau-1}^{1} \\
\vdots \\
f_{\tau-1}^{C}
\end{array}\right)+\left(\begin{array}{c}
\epsilon_{\tau}^{w} \\
\epsilon_{\tau}^{1} \\
\vdots \\
\epsilon_{\tau}^{C}
\end{array}\right),
$$

where the factors' innovations are supposed to be normally distributed and independent at all leads and lags,

\footnotetext{
${ }^{3}$ According to the statistical properties of our database, we assume that the observable variables are expressed in terms of growth rate.
} 


$$
\left(\begin{array}{c}
\epsilon_{\tau}^{w} \\
\epsilon_{\tau}^{1} \\
\vdots \\
\epsilon_{\tau}^{C}
\end{array}\right) \stackrel{i i d}{\sim} N\left(\left[\begin{array}{c}
0 \\
0 \\
\vdots \\
0
\end{array}\right],\left[\begin{array}{cccc}
\sigma_{w}^{2} & 0 & \ldots & 0 \\
0 & \sigma_{1}^{2} & \ldots & 0 \\
\vdots & \vdots & \ddots & \vdots \\
0 & 0 & \ldots & \sigma_{C}^{2}
\end{array}\right]\right)
$$

By assuming independence among $\left\{F_{\tau}^{W}, f_{\tau}^{1}, \ldots, f_{\tau}^{C}\right\}$ (all the off-diagonal elements of the VAR equal to zero) and some sign restrictions, factors are separately identified conditional on a scale normalization. However, Bai and Wang (2015) have shown that orthogonality between factors is a sufficient, but not necessary, condition for identification purposes. In other words, the VAR specification could be generalized by changing equation (5) to

$$
\underbrace{\left(\begin{array}{c}
F_{\tau}^{w} \\
f_{\tau}^{1} \\
\vdots \\
f_{\tau}^{C}
\end{array}\right)}_{\mathbf{F}_{\tau}}=\underbrace{\left(\begin{array}{cccc}
\phi_{w w} & \phi_{w 1} & \ldots & \phi_{w C} \\
\phi_{1 w} & \phi_{11} & \ldots & \phi_{1 C} \\
\vdots & \vdots & \ddots & \vdots \\
\phi_{C w} & \phi_{C 1} & \ldots & \phi_{C C}
\end{array}\right)}_{\Phi(1)} \underbrace{\left(\begin{array}{c}
F_{\tau-1}^{w} \\
f_{\tau-1}^{1} \\
\vdots \\
f_{\tau-1}^{C}
\end{array}\right)}_{\mathbf{F}_{\tau-1}}+\underbrace{\left(\begin{array}{c}
\epsilon_{\tau}^{w} \\
\epsilon_{\tau}^{1} \\
\vdots \\
\epsilon_{\tau}^{C}
\end{array}\right)}_{\xi_{\tau}} .
$$

without losing the possibility of identifying the unobserved factors. According to Proposition 3 in Bai and Wang (2015), defining a dynamic factor model as in (1), (2), (7), and (6), the factor model is uniquely identified just setting $\sigma_{w}^{2}=\sigma_{1}^{2}=\cdots=\sigma_{C}^{2}=1$, with $B_{1}^{w}$ and $\left\{B_{c}\right\}_{c=1}^{C}$ being

lower triangular with strictly positive diagonal terms, and $\left[\begin{array}{ll}B_{c}^{w} & B_{c}\end{array}\right]$ being full column rank matrices for $c=1, \ldots, C$. Assuming only one world factor and one country factor per country, the sign identification is similar to that in Kose et al. (2003), Crucini et al. (2011), and many others. Taking advantage of the mentioned proposition, the present paper assumes a dynamic for the factors similar to equation (7), where "spillover" effects between factors can be captured.

\subsection{Mixed frequencies}

In many empirical applications, the economic indicators $y_{\tau}^{i c}$ are sampled at both quarterly and monthly frequencies. In this case, at least two possibilities emerge: either the model is set at the lower frequency (quarterly) and some transformation is done to the higher-frequency series (monthly), or a mixed-frequency strategy is followed.

When the first approach is selected, a common way to proceed is to aggregate the monthly variable at a quarterly frequency. Assuming $\tau$ refers to months, $y_{\tau}^{i c}$ in equation (1) would be quarterly aggregated as

$$
y_{t}^{i c}=\omega(L) y_{\tau}^{i c}=y_{\tau}^{i c}+y_{\tau-1}^{i c}+y_{\tau-2}^{i c}
$$

for $\tau=3,6, \ldots, \mathcal{T} / 3$, where $t=\tau / 3$ refers to a quarter and $\omega(L)=1+L+L^{2}$ ( $L$ being the lag operator). Therefore, equation (1) could be written as 


$$
y_{t}^{i c}=\beta_{w}^{i c} F_{t}^{w}+\beta^{i c} f_{t}^{c}+u_{t}^{i c},
$$

where $F_{t}^{w}, f_{t}^{c}$, and $u_{t}^{i c}$ are quarterly aggregated. This kind of representation would lead to writing the transition equation at a quarterly frequency and, consequently, the $\operatorname{VAR}(1)$ process of equation (7) would be equal to

$$
\mathbf{F}_{t}=\Phi(1)^{3} \mathbf{F}_{t-1}+\xi_{t}^{*}=C \mathbf{F}_{t-1}+\kappa_{t}
$$

where $C=\Phi(1)^{3}$. Foroni and Marcellino (2016) showed that, when quarterly aggregated, the term $\kappa_{t}$ in equation (10) is a vector moving average of order 1 (VMA(1)) process and, therefore, the transition equation would follow a first-order vector autoregressive moving average $(\operatorname{VARMA}(1,1))$ process as

$$
\mathbf{F}_{t}=C \mathbf{F}_{t-1}+\varsigma_{t}+\Upsilon_{\varsigma_{t-1}},
$$

where $\varsigma_{t} \sim(0, \Omega)$. As stated in Foroni and Marcellino (2016), an econometrician would be able to estimate $\hat{C}, \hat{\Upsilon}$, and $\hat{\Omega}$, but from these matrices she could not uniquely identify $\Phi .{ }^{4}$ It should be noted though, that when $\Phi$ is diagonal - as in the case of no spillover between factorsthis identification problem does not emerge. Nonetheless, Foroni and Marcellino (2016) also correctly points out that a VARMA $(1,1)$ model like the one in equation (10) would, in general, be approximated by a finite order VAR, creating further identification issues for the monthly parameters.

In other words, when it is believed that monthly and quarterly variables contain relevant information regarding the linkage between countries' business cycles, setting the model at the lower frequency would create serious identification issues for recovering factor dynamics and their mutual relationships. Therefore, a mixed-frequency setup could potentially be a better strategy to follow.

\subsubsection{Stacked approach with monthly and quarterly variables}

We follow the stacked approach representation proposed by Blasques et al. (2016) to allow a dynamic factor model with a block structure and spillovers across factors for mixing frequencies. ${ }^{5}$ These authors show that under the state-space representation, it is possible to deal with the mixing frequencies problem by stacking the higher-frequency data (monthly) into a vector of

\footnotetext{
${ }^{4}$ Foroni and Marcellino (2016) correctly indicate that the knowledge of $C=\Phi^{3}$ does not, in general, allow uniquely identifying the parameters of $\Phi$ since matrix multiplication creates non-linear combinations of the original parameters.

${ }^{5}$ Koopman and Pacce (2016) also use this approach to handle mixing frequencies in a non-linear single dynamic factor model within a Bayesian framework.
} 
observations that operates at the lower frequency (quarterly), while all of the high-frequency information is still preserved.

In Blasques et al.'s (2016) notation, monthly variables $\tilde{y}_{\tau}(\tau$ is the monthly time index) can be stacked into a quarterly observed vector $y_{t}$ ( $t$ is the quarterly time index) of the form

$$
y_{t}=\left(\begin{array}{l}
y_{t, 1} \\
y_{t, 2} \\
y_{t, 3}
\end{array}\right)=\left(\begin{array}{l}
\tilde{y}_{3(t-1)+1} \\
\tilde{y}_{3(t-1)+2} \\
\tilde{y}_{3(t-1)+3}
\end{array}\right),
$$

where $y_{t, k}$ is the $k$-th element of $y_{t}, t$ refers to the quarter the monthly observations belong to, and $k=1,2,3$ indicates the month within quarter $t$. As an example, $y_{t, 1}$ will always refer to the first month of the quarter, meaning that depending on the quarter that $t$ is referring to, the months will possibly be January, April, July, or October. Therefore, if the quarterly timespan is $t=1, \ldots, T$, the length of the monthly series will be $\tau=1, \ldots, 3 T$.

Within this context, autoregressive processes could be written with the stacked approach through a vector autoregressive (VAR) process where $y_{t}$ depends on its own lags. As an example, an $\operatorname{AR}(1)$ process $\tilde{y}_{\tau}=\phi_{y} \tilde{y}_{\tau-1}+\tilde{\varepsilon}_{\tau}$, where $\tilde{\varepsilon}_{\tau} \stackrel{i i d}{\sim} N\left(0, \sigma_{\varepsilon}^{2}\right)$, could be written using (12) as

$$
y_{t}=T^{*} y_{t-1}+R \varepsilon_{t},
$$

where

$$
T^{*}=\left(\begin{array}{ccc}
0 & 0 & \phi_{y} \\
0 & 0 & \phi_{y}^{2} \\
0 & 0 & \phi_{y}^{3}
\end{array}\right), \quad R=\left(\begin{array}{ccc}
1 & 0 & 0 \\
\phi_{y} & 1 & 0 \\
\phi_{y}^{2} & \phi_{y} & 1
\end{array}\right)
$$

A quarterly variable $\left(x_{t}\right)$ is added easily in (13) by noting that monthly observations already operate at a quarterly frequency. Assuming $x_{t}$ also follows an $\operatorname{AR}(1)$ process given by $x_{t}=$ $\phi_{x} x_{t-1}+\eta_{t}$, with $\eta_{t} \stackrel{i i d}{\sim} N\left(0, \sigma_{\eta}^{2}\right)$, Blasques et al. (2016) propose the following mixed-frequency representation:

$$
\left(\begin{array}{c}
x_{t} \\
y_{t, 1} \\
y_{t, 2} \\
y_{t, 3}
\end{array}\right)=\left(\begin{array}{cccc}
\phi_{x} & 0 & 0 & 0 \\
0 & 0 & 0 & \phi_{y} \\
0 & 0 & 0 & \phi_{y}^{2} \\
0 & 0 & 0 & \phi_{y}^{3}
\end{array}\right)\left(\begin{array}{c}
x_{t-1} \\
y_{t-1,1} \\
y_{t-1,2} \\
y_{t-1,3}
\end{array}\right)+\left(\begin{array}{cccc}
\phi_{x} & 0 & 0 & 0 \\
0 & 1 & 0 & 0 \\
0 & \phi_{y} & 1 & 0 \\
0 & \phi_{y}^{2} & \phi_{y} & 1
\end{array}\right)\left(\begin{array}{c}
\eta_{t} \\
\varepsilon_{t, 1} \\
\varepsilon_{t, 2} \\
\varepsilon_{t, 3}
\end{array}\right) .
$$

\subsubsection{Stacked framework for VAR processes}

Continuing the line of reasoning detailed previously, we delineate how to adapt the stacked framework to deal with VAR processes. Consider a VAR(1) process with two monthly variables, $y_{\tau}^{1}$ and $y_{\tau}^{2}$. Under the classical representation, this process could be written as 


$$
\left(\begin{array}{l}
y_{\tau}^{1} \\
y_{\tau}^{2}
\end{array}\right)=\left(\begin{array}{ll}
\phi_{11} & \phi_{12} \\
\phi_{21} & \phi_{22}
\end{array}\right)\left(\begin{array}{l}
y_{\tau-1}^{1} \\
y_{\tau-1}^{2}
\end{array}\right)+\left(\begin{array}{l}
\varepsilon_{\tau}^{1} \\
\varepsilon_{\tau}^{2}
\end{array}\right)
$$

where

$$
\left(\begin{array}{l}
\varepsilon_{\tau}^{1} \\
\varepsilon_{\tau}^{2}
\end{array}\right) \sim N I D\left(\left(\begin{array}{l}
0 \\
0
\end{array}\right),\left(\begin{array}{cc}
\sigma_{\varepsilon_{1}}^{2} & 0 \\
0 & \sigma_{\varepsilon_{2}}^{2}
\end{array}\right)\right) .
$$

Using equation (12), all monthly observations and innovations $\left\{y_{\tau}^{1}, y_{\tau}^{2}, \varepsilon_{\tau}^{1}, \varepsilon_{\tau}^{2}\right\}_{\tau=1}^{3 T}$ can be written as stacked quarterly vectors $\left\{y_{t}^{1}, y_{t}^{2}, \varepsilon_{t}^{1}, \varepsilon_{t}^{2}\right\}_{t=1}^{T}$ (remembering that $t$ is a quarterly time index). With this notation, the $\operatorname{VAR}(1)$ process characterized in $(16)$ for $(t, 1),(t, 2)$, and $(t, 3)$ can be described as

$$
\begin{aligned}
& (t, 1) \longrightarrow\left\{\left(\begin{array}{l}
y_{t, 1}^{1} \\
y_{t, 1}^{2}
\end{array}\right)=\left(\begin{array}{ll}
\phi_{11} & \phi_{12} \\
\phi_{21} & \phi_{22}
\end{array}\right)\left(\begin{array}{l}
y_{t-1,3}^{1} \\
y_{t-1,3}^{2}
\end{array}\right)+\left(\begin{array}{c}
\varepsilon_{t, 1}^{1} \\
\varepsilon_{t, 1}^{2}
\end{array}\right),\right. \\
& (t, 2) \longrightarrow\left\{\begin{array}{l}
y_{t, 2}^{1} \\
y_{t, 2}^{2}
\end{array}\right)=\left(\begin{array}{ll}
\phi_{11} & \phi_{12} \\
\phi_{21} & \phi_{22}
\end{array}\right)\left(\begin{array}{l}
y_{t, 1}^{1} \\
y_{t, 1}^{2}
\end{array}\right)+\left(\begin{array}{c}
\varepsilon_{t, 2}^{1} \\
\varepsilon_{t, 2}^{2}
\end{array}\right), \\
& (t, 3) \longrightarrow\left\{\begin{array}{l}
y_{t, 3}^{1} \\
y_{t, 3}^{2}
\end{array}\right)=\left(\begin{array}{ll}
\phi_{11} & \phi_{12} \\
\phi_{21} & \phi_{22}
\end{array}\right)\left(\begin{array}{l}
y_{t, 2}^{1} \\
y_{t, 2}^{2}
\end{array}\right)+\left(\begin{array}{c}
\varepsilon_{t, 3}^{1} \\
\varepsilon_{t, 3}^{2}
\end{array}\right),
\end{aligned}
$$

It should be noted that both the variables for the second month $(t, 2)$ and the third month $(t, 3)$ of the quarter could be written in terms of the last moth of the previous quarter $(t-1,3)$. This can be done by substituting $\left(y_{t, 1}^{1}, y_{t, 1}^{2}\right)^{\prime}$ in equation (19) by equation (18). The obtained result could then be used to replace $\left(y_{t, 2}^{1}, y_{t, 2}^{2}\right)^{\prime}$ in equation (20). After some algebra, it can be shown that

$$
\begin{aligned}
\left(\begin{array}{c}
y_{t, 2}^{1} \\
y_{t, 2}^{2}
\end{array}\right)= & \left(\begin{array}{ll}
\sum_{i=1}^{2} \phi_{1 i} \phi_{i 1} & \sum_{i=1}^{2} \phi_{1 i} \phi_{i 2} \\
\sum_{i=1}^{2} \phi_{2 i} \phi_{i 1} & \sum_{i=1}^{2} \phi_{2 i} \phi_{i 2}
\end{array}\right)\left(\begin{array}{l}
y_{t-1,3}^{1} \\
y_{t-1,3}^{2}
\end{array}\right)+\left(\begin{array}{ll}
\phi_{11} & \phi_{12} \\
\phi_{21} & \phi_{22}
\end{array}\right)\left(\begin{array}{l}
\varepsilon_{t, 1}^{1} \\
\varepsilon_{t, 1}^{2}
\end{array}\right)+\left(\begin{array}{c}
\varepsilon_{t, 2}^{1} \\
\varepsilon_{t, 2}^{2}
\end{array}\right), \\
\left(\begin{array}{c}
y_{t, 3}^{1} \\
y_{t, 3}^{2}
\end{array}\right)= & \left(\begin{array}{ll}
\sum_{j=1}^{2} \sum_{i=1}^{2} \phi_{1 j} \phi_{j i} \phi_{i 1} & \sum_{j=1}^{2} \sum_{i=1}^{2} \phi_{1 j} \phi_{j i} \phi_{i 2} \\
\sum_{j=1}^{2} \sum_{i=1}^{2} \phi_{2 j} \phi_{j i} \phi_{i 1} & \sum_{j=1}^{2} \sum_{i=1}^{2} \phi_{2 j} \phi_{j i} \phi_{i 2}
\end{array}\right)\left(\begin{array}{l}
y_{t-1,3}^{1} \\
y_{t-1,3}^{2}
\end{array}\right)+ \\
& \left(\begin{array}{ll}
\sum_{i=1}^{2} \phi_{1 i} \phi_{i 1} & \sum_{i=1}^{2} \phi_{1 i} \phi_{i 2} \\
\sum_{i=1}^{2} \phi_{2 i} \phi_{i 1} & \sum_{i=1}^{2} \phi_{2 i} \phi_{i 2}
\end{array}\right)\left(\begin{array}{l}
\varepsilon_{t, 1}^{1} \\
\varepsilon_{t, 1}^{2}
\end{array}\right)+\left(\begin{array}{ll}
\phi_{11} & \phi_{12} \\
\phi_{21} & \phi_{22}
\end{array}\right)\left(\begin{array}{l}
\varepsilon_{t, 2}^{1} \\
\varepsilon_{t, 2}^{2}
\end{array}\right)+\left(\begin{array}{l}
\varepsilon_{t, 3}^{1} \\
\varepsilon_{t, 3}^{2}
\end{array}\right) .
\end{aligned}
$$

Using (18), (21), and (22), the $\operatorname{VAR}(1)$ process can be written in matrix form through the stacked vectors $y_{t}^{1}, y_{t}^{2}, \varepsilon_{t}^{1}$, and $\varepsilon_{t}^{2}$ as

$$
Y_{t}^{q}=T^{*} Y_{t-1}^{q}+R \zeta_{t}
$$


with matrices

$$
\begin{aligned}
& Y_{t}^{q}=\left(\begin{array}{llllll}
y_{t, 1}^{1} & y_{t, 2}^{1} & y_{t, 3}^{1} & y_{t, 1}^{2} & y_{t, 2}^{2} & y_{t, 3}^{2}
\end{array}\right)^{\prime}, \quad \quad \zeta_{t}=\left(\begin{array}{llllll}
\varepsilon_{t, 1}^{1} & \varepsilon_{t, 2}^{1} & \varepsilon_{t, 3}^{1} & \varepsilon_{t, 1}^{2} & \varepsilon_{t, 2}^{2} & \varepsilon_{t, 3}^{2}
\end{array}\right)^{\prime},
\end{aligned}
$$

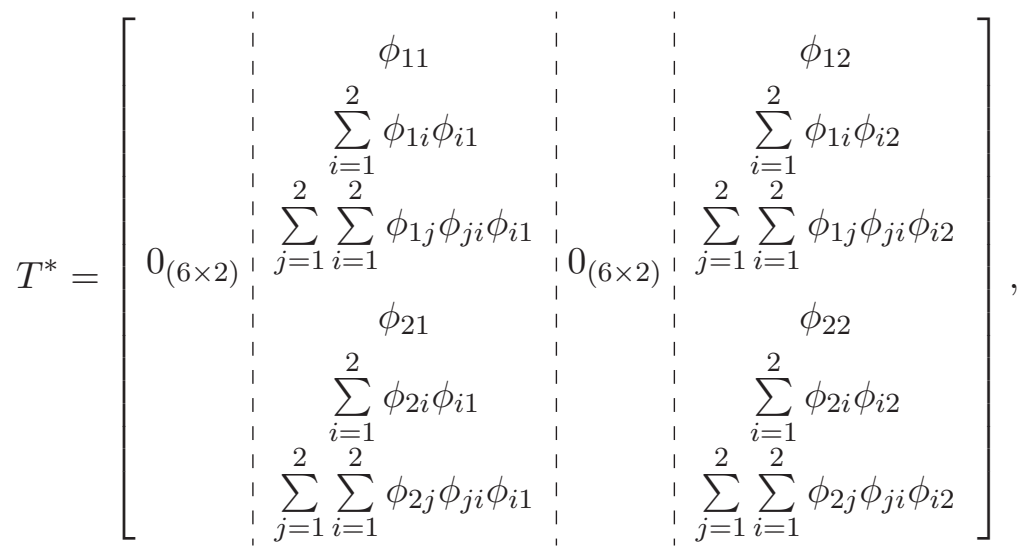

$$
\begin{aligned}
& R=\left(\begin{array}{cccccc}
1 & 0 & 0 & 0 & 0 & 0 \\
\phi_{11} & 1 & 0 & \phi_{12} & 0 & 0 \\
\sum_{i=1}^{2} \phi_{1 i} \phi_{i 1} & \phi_{11} & 1 & \sum_{i=1}^{2} \phi_{1 i} \phi_{i 2} & \phi_{12} & 0 \\
0 & 0 & 0 & 1 & 0 & 0 \\
\phi_{21} & 0 & 0 & \phi_{22} & 1 & 0 \\
\sum_{i=1}^{2} \phi_{2 i} \phi_{i 1} & \phi_{21} & 0 & \sum_{i=1}^{2} \phi_{2 i} \phi_{i 2} & \phi_{22} & 1
\end{array}\right)
\end{aligned}
$$

and $\zeta_{t} \stackrel{\text { iid }}{\sim} N\left(0_{(6,1)}, \Sigma\right)$, where $\Sigma=\operatorname{diag}\left(\sigma_{\varepsilon_{1}}^{2}, \sigma_{\varepsilon_{1}}^{2}, \sigma_{\varepsilon_{1}}^{2}, \sigma_{\varepsilon_{2}}^{2}, \sigma_{\varepsilon_{2}}^{2}, \sigma_{\varepsilon_{2}}^{2}\right)$. In Appendix A, it is shown how to derive $\operatorname{VAR}(1)$ and $\operatorname{VAR}(2)$ processes when increasing the number of variables involved in the VAR.

\subsubsection{Stacking the multiple dynamic factor model with a block structure}

Models trying to capture the evolution of both the international and country cycles have, in general, been studied restricting observable variables to being expressed in the same unit of measure (e.g., annual, quarterly, or monthly growth rate) and having the same length. To the best knowledge of the authors, the only exception in the literature is Aruoba et al. (2011), who estimate a hierarchical multicountry model using quarterly and monthly variables.

Based on a dynamic factor model that allows for mixed-frequency data and missing observations, as proposed by Mariano and Murasawa (2003), Camacho and Perez-Quiros (2010), and Aruoba and Diebold (2010), among others, they first estimate each country factor and then decompose these factors into a component common to all and an idiosyncratic component. Departing from this approach, we propose an alternative way to deal with mixed frequencies in the context of a multiple dynamic factor model with a block structure, which is also able to deal 
with missing observations. By contrast, our approach has the important feature of fitting the model to deal with non-orthogonal factors, allowing for the possibility of computing "spillover" effects.

Mixed-frequencies are allowed in dynamic factor models by using the stacked approach already shown in Subsection 2.2.1. Beginning with monthly variables, the dynamics can easily be represented in terms of monthly factors as in equation (1). In order to simplify exposition, we assume that $u_{\tau}^{i c}=\varepsilon_{\tau}^{i c}$, which implies

$$
y_{\tau}^{i c}=\beta_{w_{c}}^{i c} F_{\tau}^{w}+\beta^{i c} f_{\tau}^{c}+\varepsilon_{\tau}^{i c},
$$

where $\varepsilon_{\tau}^{i c} \stackrel{i i d}{\sim} N\left(0, \sigma_{\varepsilon^{i c}}^{2}\right)$.

Let us assume that we add a quarterly variable for a country, $c\left(x_{t}^{i c}\right)$. Its quarterly dynamics will be approximated by the monthly dynamics of the common, the country, and the idiosyncratic components as follows:

$$
\begin{aligned}
x_{t}^{i c}= & \beta_{1, w}^{i c} F_{3(t-1)+1}^{w}+\beta_{2, w}^{i c} F_{3(t-1)+2}^{w}+\beta_{3, w}^{i c} F_{3(t-1)+3}^{w}+ \\
& \beta_{1}^{i c} f_{3(t-1)+1}^{c}+\beta_{2}^{i c} f_{3(t-1)+2}^{c}+\beta_{3}^{i c} f_{3(t-1)+3}^{c}+\eta_{t}^{i c},
\end{aligned}
$$

where $\eta_{t}^{i c} \stackrel{i i d}{\sim} N\left(0, \sigma_{\eta^{i c}}^{2}\right)$. Blasques et al. (2016) impose the simplifying assumption that the loading factors are fixed for all of the months of the respective quarter, which implies that $\beta_{k, w}^{i c}=\beta_{w}^{i c}$, and $\beta_{k}^{i c}=\beta^{i c}$ for $k=1,2,3 .{ }^{6}$ When this is the case, equation (24) could be written using the stacked approach for the factors as

$$
x_{t}^{i c}=\left(\begin{array}{lll}
\beta_{w}^{i c} & \beta_{w}^{i c} & \beta_{w}^{i c}
\end{array}\right) \hat{F}_{t}^{w}+\left(\begin{array}{lll}
\beta^{i c} & \beta^{i c} & \beta^{i c}
\end{array}\right) \hat{f}_{t}^{c}+\eta_{t}^{i c} .
$$

Including both monthly and quarterly variables within the model is straightforward. Assume, for exposition reasons, a two-country multilevel model with one monthly and one quarterly variable per country, where factors follow a $\operatorname{VAR}(1)$. The state-space representation of (23) and (25) becomes

$$
\begin{array}{rlrl}
X_{t} & =Z F_{t}^{*}+\gamma_{t} & & \gamma_{t} \sim N(0, H), \\
F_{t+1}^{*} & =T^{*} F_{t}^{*}+R \xi_{t} & \xi_{t} \sim N(0, Q),
\end{array}
$$

where

$$
\begin{aligned}
X_{t} & =\left(\begin{array}{lllllllll}
y_{t, 1}^{11} & y_{t, 2}^{11} & y_{t, 3}^{11} & x_{t}^{21} & y_{t, 1}^{12} & y_{t, 2}^{12} & y_{t, 3}^{12} & x_{t}^{22}
\end{array}\right)^{\prime}, \\
F_{t}^{*} & =\left(\begin{array}{lllllllll}
F_{t, 1}^{w} & F_{t, 2}^{w} & F_{t, 3}^{w} & f_{t, 1}^{1} & f_{t, 2}^{1} & f_{t, 3}^{1} & f_{t, 1}^{2} & f_{t, 2}^{2} & f_{t, 3}^{2}
\end{array}\right)^{\prime}, \\
\gamma_{t} & =\left(\begin{array}{lllllllll}
\varepsilon_{t, 1}^{11} & \varepsilon_{t, 2}^{11} & \varepsilon_{t, 3}^{11} & \eta_{t}^{21} & \varepsilon_{t, 1}^{12} & \varepsilon_{t, 2}^{12} & \varepsilon_{t, 3}^{12} & \eta_{t}^{22}
\end{array}\right)^{\prime}, \\
\xi_{t} & =\left(\begin{array}{lllllllll}
\epsilon_{t, 1}^{w} & \epsilon_{t, 2}^{w} & \epsilon_{t, 3}^{w} & \epsilon_{t, 1}^{1} & \epsilon_{t, 2}^{1} & \epsilon_{t, 3}^{1} & \epsilon_{t, 1}^{2} & \epsilon_{t, 2}^{2} & \epsilon_{t, 3}^{2}
\end{array}\right)^{\prime},
\end{aligned}
$$

\footnotetext{
${ }^{6}$ This is not a restrictive assumption. However, allowing for different loading factors across the months of the quarter will increase the number of parameters considerably.
} 
$Z=\left(\begin{array}{ccc}B_{w_{1}} & B_{1} & 0_{(4 \times 3)} \\ B_{w_{2}} & 0_{(4 \times 3)} & B_{2}\end{array}\right) \quad$ where $B_{w_{c}}=\left(\begin{array}{ccc}\beta_{w}^{1 c} & 0 & 0 \\ 0 & \beta_{w}^{1 c} & 0 \\ 0 & 0 & \beta_{w}^{1 c} \\ \beta_{w}^{2 c} & \beta_{w}^{2 c} & \beta_{w}^{2 c}\end{array}\right) \quad$ and $\quad B_{c}=\left(\begin{array}{ccc}\beta^{1 c} & 0 & 0 \\ 0 & \beta^{1 c} & 0 \\ 0 & 0 & \beta^{1 c} \\ \beta^{2 c} & \beta^{2 c} & \beta^{2 c}\end{array}\right)$ for $c=\{1,2\} . Q$ and $H$ are both diagonal matrices for which entries in the main diagonal are determined, respectively, by the vectors $\left(\sigma_{w}^{2}, \sigma_{w}^{2}, \sigma_{w}^{2}, \sigma_{1}^{2}, \sigma_{1}^{2}, \sigma_{1}^{2}, \sigma_{2}^{2}, \sigma_{2}^{2}, \sigma_{2}^{2}\right)$ and $\left(\sigma_{\varepsilon^{11}}^{2}, \sigma_{\varepsilon^{11}}^{2}, \sigma_{\varepsilon^{11}}^{2}, \sigma_{\eta^{21}}^{2}\right.$, $\left.\sigma_{\varepsilon^{12}}^{2}, \sigma_{\varepsilon^{12}}^{2}, \sigma_{\varepsilon^{12}}^{2}, \sigma_{\eta^{22}}^{2}\right)$. Matrices $T^{*}$ and $R$ are derived following the line of reasoning of subsection 2.2.1 and are equal to

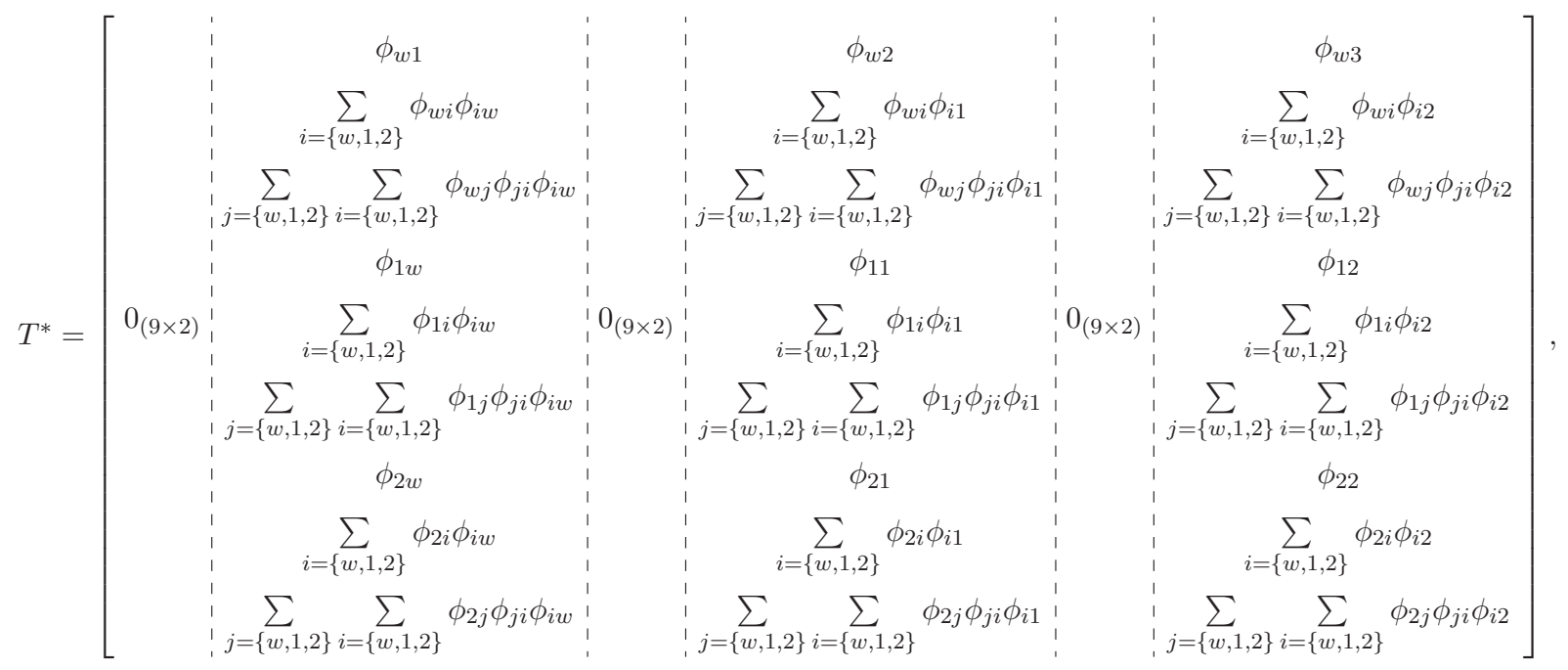

$$
R=\left(\begin{array}{ccccccccc}
1 & 0 & 0 & 0 & 0 & 0 & 0 & 0 & 0 \\
\phi_{w w} & 1 & 0 & \phi_{w 1} & 0 & 0 & \phi_{w 2} & 0 & 0 \\
\sum_{i=\{w, 1,2\}} \phi_{w i} \phi_{i w} & \phi_{w w} & 1 & \sum_{i=\{w, 1,2\}} \phi_{w i} \phi_{i 1} & \phi_{w 1} & 0 & \sum_{i=\{w, 1,2\}} \phi_{w i} \phi_{i 2} & \phi_{w 2} & 0 \\
0 & 0 & 0 & 1 & 0 & 0 & 0 & 0 & 0 \\
\phi_{1 w} & 0 & 0 & \phi_{11} & 1 & 0 & \phi_{12} & 0 & 0 \\
\sum_{i=\{w, 1,2\}} \phi_{1 i} \phi_{i w} & \phi_{1 w} & 0 & \sum_{i=\{w, 1,2\}} \phi_{1 i} \phi_{i 1} & \phi_{11} & 1 & \sum_{i=\{w, 1,2\}} \phi_{1 i} \phi_{i 2} & \phi_{12} & 0 \\
0 & 0 & 0 & 0 & 0 & 0 & 1 & 0 & 0 \\
\phi_{2 w} & 0 & 0 & \phi_{21} & 0 & 0 & \phi_{22} & 1 & 0 \\
\sum_{i=\{w, 1,2\}} \phi_{2 i} \phi_{i w} & \phi_{2 w} & 0 & \sum_{i=\{w, 1,2\}} \phi_{2 i} \phi_{i 1} & \phi_{21} & 0 & \sum_{i=\{w, 1,2\}} \phi_{2 i} \phi_{i 2} & \phi_{22} & 1
\end{array}\right) .
$$

In Appendix A.1, the full derivation of matrices $T^{*}$ and $R$ is shown for the case of a $\operatorname{VAR}(1)$ process when 3 monthly variables are included. It should be noted that the transition equation of (26) corresponds to that particular case.

According to Proposition 3 in Bai and Wang (2015), three identification issues arise when factors are not orthogonal to each other. First, in order to identify the scale of the factors, it 
needs to be assumed that $\sigma_{w}^{2}=\sigma_{1}^{2}=\sigma_{2}^{2}=1$ ( or $Q=I_{9}$ ). In addition, for a unique identification $B_{w_{1}}, B_{1}$, and $B_{2}$ should be lower triangular matrices with strictly positive diagonal terms, and $\left[B_{w_{c}}, B_{c}\right]$ should be full column rank matrices for $c=\{1,2\}$. These restrictions can be achieved by using the sign identification scheme proposed by Kose et al. (2003), Crucini et al. (2011), and many others. This means restricting the factor loadings for the "world factor" of the first monthly variable of the first country in the list to being strictly positive (e.g., industrial production index of the US), while country factors should have strictly positive factor loadings of the first monthly variable of each country (e.g., industrial production index of each country).

\section{Estimation strategy}

Assume a multiple dynamic factor model with a block structure that could be written using the state-space representation as in (26). Suppose there are $C$ countries with $n_{c}$ variables per country, while the dynamics for the $(C+1)$ factors follow a $\operatorname{VAR}(1)$ process and the innovations errors of the $N=\sum_{c=1}^{C} n_{c}$ observable variables follow an $\operatorname{AR}(1)$ process. Then, denoting by $\varphi$ the set of parameters $\left\{\phi_{w w} \cup\left\{\left\{\phi_{w c}, \phi_{c w}\right\} \cup\left\{\phi_{c j}, \phi_{j c}\right\}_{j=1}^{C} \cup\left\{\beta_{w}^{i c}, \beta^{i c}, \sigma_{\varepsilon^{i c}}^{2}, \phi_{1}^{i c}\right\}_{i=1}^{n_{c}}\right\}_{c=1}^{C}\right\}$, there are a total of $N \times 4+(C+1)^{2}$ parameters $^{7}$ and $C+1$ unobserved factors that need to be estimated.

For this purpose, in this section we develop a Bayesian approach. Specifically, the estimation basically relies on a Metropolis-Hastings algorithm within a Gibbs sampling procedure where the problem is reduced to a number of draws - accounting for the presence of missing observationsfrom the posterior distribution of the parameters given the factors $p\left(\varphi \mid F^{w}, f^{1}, \ldots, f^{C}\right)$ and from the posterior distribution of the factors conditional on parameters $p\left(F^{w}, f^{1}, \ldots, f^{C} \mid \varphi\right)$. The algorithm basically consists of 5 blocks, briefly described below. In Appendix B, a detailed explanation about each of the steps related to the sampling of parameters is given. Starting and prior values are described in Appendix C.

\subsection{Sampling algorithm}

i. Steps 1 and 2: Drawing loading factors and innovation errors.

If we know the true factors, each of the equations described in (1) could be evaluated as an independent regression with Gaussian autoregressive errors. If we also assume that the autoregressive parameters in (2) are known, each equation (1) could be written as a quasidifferentiated equation with homoscedastic and uncorrelated residuals. Then, it is possible to post a normal-gamma prior, where the conditional posterior for $\beta_{w}^{i c}, \beta^{i c}$ and $\sigma_{\varepsilon^{i c}}$ is also normal-gamma.

\footnotetext{
${ }^{7}$ Including 7 countries and 4 variables per country means 176 parameters.
} 
ii. Step 3: Drawing autoregressive coefficients for observable variables.

Each of the equations described by (2) can also be drawn as an independent regression once the idiosyncratic components, $u_{t}^{i c}$, and the innovation variance, $\sigma_{\varepsilon^{i c}}^{2}$, are treated as if they were known. Since residuals are white noise, the usual normal prior with a normal conditional posterior can be post for the regression coefficients. ${ }^{8}$

iii. Step 4: Drawing VAR coefficients conditional on factors.

Once the world and country factors are assumed as given, and noting that the variancecovariance matrix for factor innovations is assumed to be known and diagonal for identification reasons, the VAR process described in equation (7) can be easily estimated. As in the previous step, a normal prior with a normal conditional posterior can be assumed, in this case to estimate the VAR coefficients.

iv. Step 5: Sampling latent factors given parameters.

One common strategy when latent factors of multilevel dynamic factor models need to be estimated is to draw each latent factor conditional on the rest of the factors and parameters (see Kose et al., 2003 and, Crucini et al., 2011, among others). However, this approach is not suitable when factors are non-orthogonal between each other. Alternatively, the state vector described in (26), which contains all latent factors, can be drawn conditional on observations and parameters by means of a simulation smoother:

$$
F_{t \mid T}^{*} \sim p\left(F_{t}^{*} \mid X_{t}, Z, T^{*}, R, H, Q, t=1, \ldots, T\right) .
$$

Among others, Carter and Kohn (1994), Durbin and Koopman (2002), and Bai and Wang (2015) propose different alternatives for the simulation-smoother algorithm. In this paper, we follow Durbin and Koopman (2002) because the algorithm has been proven to be computationally fast when $T^{*}$ and $T$ are large and it deals easily with missing observations, which facilitates the empirical analysis. ${ }^{9}$

When serially correlated innovations for observable variables are assumed, the state-space representation can be written in terms of quasi-differenced variables (using equation 32 and equation 36) depending on quasi-differenced factors. Kim and Nelson (1999) propose a "compact" state-space representation based on this quasi-differentiate approach (see equa-

\footnotetext{
${ }^{8}$ A Metropolis-Hastings algorithm within Gibbs sampling is used in this step in order to discard explosive roots.

${ }^{9}$ Following Durbin and Koopman (2001), pp. 92-93, a Kalman filter is applied to a modified version of the state-space representation where, at each $t$, rows (or columns) of the measurement equation's matrices that correspond to missing observations are removed.
} 
tion $8.33^{\prime}$ in their book), which is adapted to deal with the stacked state-space representation by Koopman and Pacce (2016) within a non-linear framework.

\section{Simulation study}

In this section, we analyze the performance of the estimation method described above in the context of mixing frequencies when different numbers of quarterly variables are included in the model. For this purpose, we use data-generating processes (DGPs), which allow controlling the signal-to-noise ratio and the serial correlation in both the factor dynamics and the idiosyncratic terms. In addition, the model allows mixed frequencies for variables and non-orthogonality across factors. 10

Assuming a total of $C$ countries, the dynamic factor model is defined as in (7) and (6). A $\operatorname{VAR}(2)$ will be assumed for the dynamics of the factors, which can be expressed in the companion form as

$$
\underbrace{\left(\begin{array}{c}
\mathbf{F}_{\tau} \\
\mathbf{F}_{\tau-1}
\end{array}\right)}_{\mathcal{F}_{\tau}}=\underbrace{\left(\begin{array}{ll}
\Phi(1) & \Phi(2) \\
I_{1+C} & 0_{1+C}
\end{array}\right)}_{\mathrm{T}^{*}} \underbrace{\left(\begin{array}{c}
\mathbf{F}_{\tau-1} \\
\mathbf{F}_{\tau-2}
\end{array}\right)}_{\mathcal{F}_{\tau-1}}+\underbrace{\left(\begin{array}{c}
\xi_{\tau} \\
0_{1+C}
\end{array}\right)}_{\mathcal{E}_{\tau}},
$$

where $\mathcal{E}_{\tau} \stackrel{i i d}{\sim} N\left(0, \Sigma_{\mathcal{E}}\right)$, and $\Sigma_{\mathcal{E}}$ is a matrix of zeros except for the first $1+C$ elements of the main diagonal, which are equal to $1 . \Phi(1)$ and $\Phi(2)$ are defined below fulfilling the assumption of stationarity of the factors. Variables $i=1, \ldots, n_{c}$ for each country $c$ are generated as follows:

$$
\begin{aligned}
& \text { if } i \text { is monthly } \rightarrow \quad y_{\tau}^{i c}=\beta_{w}^{i c} F_{\tau}^{w}+\beta^{i c} f_{\tau}^{c}+u_{\tau}^{i c}, \quad \tau=1, \ldots, 3 T, \\
& \text { if } i \text { is quarterly } \rightarrow \quad x_{t}^{i c}=\sum_{h=1}^{3} \beta_{w}^{i c} F_{(t-1) 3+h}^{w}+\sum_{h=1}^{3} \beta^{i c} f_{(t-1) 3+h}^{c_{c}}+u_{t}^{i c}, \quad t=1, \ldots, T,
\end{aligned}
$$

where the loading factors are generated from a normal distribution $\left(\beta_{w}^{i c} \stackrel{\mathrm{d}}{=} \beta^{i c} \sim N(0,1)\right)$.

We define $\rho_{i c}^{k}$ as the parameter that governs the signal-to-noise ratio for each variable (those signal-to-noise ratios are drawn from a uniform distribution on $[.2, .8]) \cdot \rho_{i c}^{k}$ restricts the variance of the innovations errors, which for monthly and quarterly variables are assumed to follow an $\mathrm{AR}(2)$ process described by

$$
\begin{array}{cl}
\text { if } i \text { is monthly } \rightarrow \quad u_{\tau}^{i c}=\phi_{1}^{i c} u_{\tau-1}^{i c}+\phi_{2}^{i c} u_{\tau-2}^{i c}+\varepsilon_{\tau}^{i c}, & \varepsilon_{\tau}^{i c} \stackrel{i i d}{\sim} N\left(0, \nu_{i c}^{m}\right), \\
\text { if } i \text { is quarterly } \rightarrow \quad u_{t}^{i c}=\phi_{1}^{i c} u_{t-1}^{i c}+\phi_{2}^{i c} u_{t-2}^{i c}+\eta_{t}^{i c}, & \eta_{t}^{i c} \stackrel{i i d}{\sim} N\left(0, \nu_{i c}^{q}\right), \\
\nu_{i c}^{k}=\frac{1-\phi_{2}^{i c}}{\left(1+\phi_{2}^{i c}\right)\left[\left(1-\phi_{2}^{i c}\right)^{2}-\left(\phi_{1}^{i c}\right)^{2}\right]} \alpha_{i c}^{k} & \\
\left.\alpha_{i c}^{k}=\frac{\rho_{i c}^{k}}{1-\rho_{i c}^{k}}\left(\Sigma_{\mathcal{F} k_{1,1}}^{-1}\left(\beta_{w}^{i c}\right)^{2}+\sum_{j=1}^{C} \Sigma_{\mathcal{F} k_{(j+1),(j+1)}^{-1}}\left(\beta^{i j}\right)^{2}\right)\right\} & \text { for } k=\{m, q\},
\end{array}
$$

\footnotetext{
${ }^{10}$ Our proposed DGPs basically rely on the DGPs described in Stock and Watson (2002) and Doz et al. (2012) for the single-frequency case.
} 
where $\Sigma_{\mathcal{F} m_{h, h}}$ is the $(h, h)$ element of the variance of $\mathcal{F}_{\tau} \cdot{ }^{11}$ Similarly, $\Sigma_{\mathcal{F} q_{h, h}}$ is the $(h, h)$ element of the variance-covariance matrix of the vector of the quarterly-added factors in the companion form:

$$
\mathcal{F}_{t}=\left[\begin{array}{c}
\mathbf{F}_{t} \\
\mathbf{F}_{t-1}
\end{array}\right] \quad \text { where } \quad \mathbf{F}_{t}=\left[\begin{array}{lllll}
\sum_{h=1}^{3} F_{(t-1) 3+h}^{w} & \sum_{h=1}^{3} f_{(t-1) 3+h}^{1} & \cdots & \sum_{h=1}^{3} f_{(t-1) 3+h}^{C}
\end{array}\right]^{\prime} .
$$

We generate two-country models by changing the number of monthly and quarterly variables included in each country. In particular, if $m_{c}$ and $q_{c}$ are the number of monthly and quarterly variables included for country $c$, then each combination of $m_{c}=\{0, \ldots, 5\}$ and $q_{c}=\{0, \ldots, 5\}-$ where at least three variables are included - is simulated 100 times. It should be noted that the number of monthly variables included (when included) is relatively small, in an attempt to create a scenario similar to the one that will appear in the empirical approach. The sample size is equal to $T=100$ for $q_{c}$ (or $3 T=300$ for $m_{c}$ ), which corresponds to almost 25 years of data. ${ }^{12}$ In all cases, the $\operatorname{VAR}(2)$ process assumed for the factors is given by

$$
\left[\begin{array}{ll}
\Phi(1) & \Phi(2)
\end{array}\right]=\left[\begin{array}{cccccc}
.5 & .3 & 0 & .2 & 0 & 0 \\
-.1 & .2 & .1 & .1 & .1 & 0 \\
.2 & -.2 & .4 & .1 & -.1 & .2
\end{array}\right]
$$

which is line with the dynamic of the $\operatorname{VAR}(2)$ process that Bai and Wang (2015) use in their simulation study. The $\mathrm{AR}(2)$ process for innovations comes from setting $\phi_{1}^{i c}=.4$ and $\phi_{2}^{i c}=.2$ for all $i$ and $c$.

To evaluate the performance of the Bayesian estimation of the stacked approach, we perform two analyses. In the first analysis, we examine the performance of the model in obtaining accurate inferences of the factors. For this purpose, we compute the adjusted $R$-squared of regressing each estimated factor on the true one, which can be interpreted as a measure of the goodness of fit. Figure 1 shows the median of the adjusted $R$-squared values over the 100 simulations for the common factor and for the two country-specific factors.

As expected, the factor common to all countries $\left(F^{w}\right)$ is always better assessed than the country factors $\left(F_{1}\right.$ and $\left.F_{2}\right)$. This is because the number of variables affecting $F^{w}$ is greater than those affecting each country factor. The improvements in the adjusted $R$-squared values are significant when the number of monthly variables increases, especially when the number of

\footnotetext{
${ }^{11}$ from the companion form $\operatorname{vec}\left(\Sigma_{\mathcal{F}}\right)=\left[I_{[2(1+C)]}-T \otimes T\right]^{-1} \operatorname{vec}\left(\Sigma_{\mathcal{E}}\right)$

${ }^{12}$ When increasing $m_{c}$ or $q_{c}$, the variables used in the previous step are maintained (e.g., when moving from $\left(m_{c}=3, q_{c}=0\right)$ to $\left(m_{c}=3, q_{c}=1\right)$, the three monthly variables and factors are kept and just a quarterly variable per country is added to the model.
} 
Figure 1: Adjusted $R^{2}$ of regressing estimated on true factors
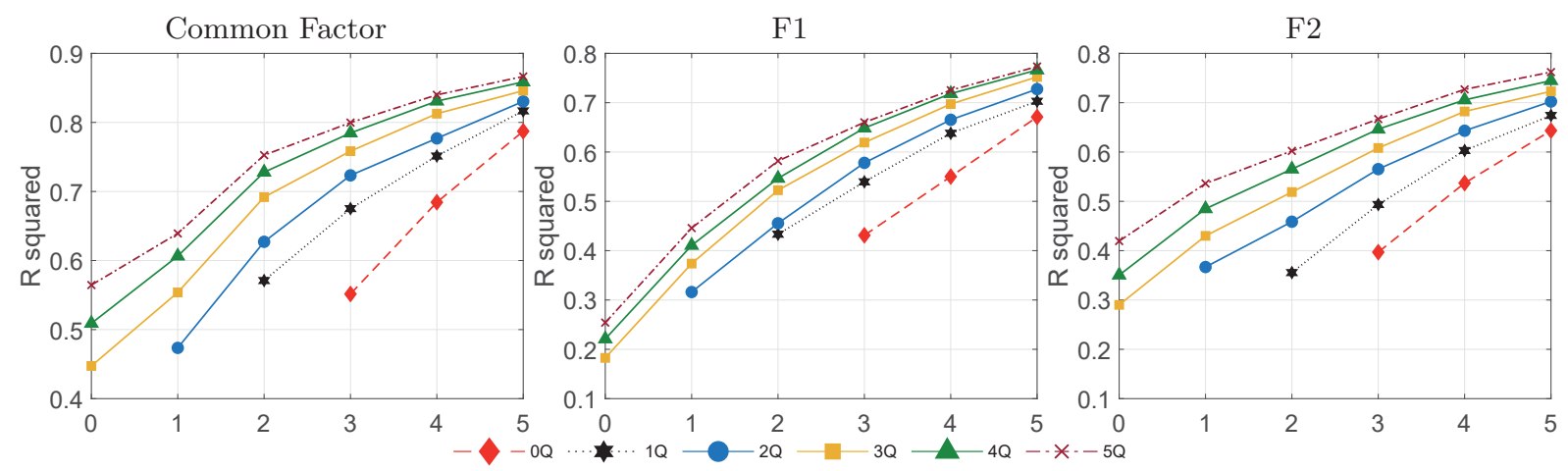

Note: Median values over 100 model simulations of each combination of $\left\{m_{c}^{i}, q_{c}^{j}\right\}$. The $x$ axes represent the number of monthly variables included per country.

quarterly variables already included in the models is relatively small. As an example, the black line with stars (which represents the case where only one quarterly variable is included) increases with the number of monthly variables added (from 2 to 5 monthly variables), and this is the case for all lines in Figure 1. This suggests exploring the mixed-frequency approach to obtain accurate inferences for the unobserved factors. ${ }^{13}$

The second analysis is related to the precision of the estimation of the VAR coefficients' governing factor dynamics. Figures 2 and 3 show the estimated coefficients for the two autoregressive matrices for each combination of $m_{c}=\{0, \ldots, 5\}$ and $q_{c}=\{0, \ldots, 5\}$. Each vertical line connects the mean of the $16 \%$ and $84 \%$ quantiles for the estimation of the VAR's parameters over the 100 simulations. The marker in every single line reflects the mean of the estimated median for each case.

Some results can be extracted from a visual inspection of the figures. The first result is that when no monthly variables are included (vertical lines that refer to 0 in the $x$ axis), it is very hard to obtain estimates different from zero for those VAR parameters that allow for spillover (all parameters off the main diagonal of $\Phi(1)$ and $\Phi(2))$. This result shouldn't be surprising because the model is trying to capture the monthly dynamics of the factors from quarterly information. However, the estimation of the elements in the main diagonal (those capturing the effects of past values of one factor on the factor itself) is relatively accurate even when no monthly series are included. These outcomes are related to the identification issues regarding the estimation of matrix $\Phi$ when only quarterly variables are included in the model (see footnote 4 in Section

\footnotetext{
${ }^{13}$ It should be noted that under the stacked approach, when only quarterly variables are included, a monthly factor is still obtained and, therefore, it is possible to compute the adjusted R-squared.
} 
Figure 2: Factor's VAR coefficients for $\Phi(1)$ :

True values and mean of $16 \%$ and $84 \%$ estimated quantiles

$\phi_{11}^{1}=.5$
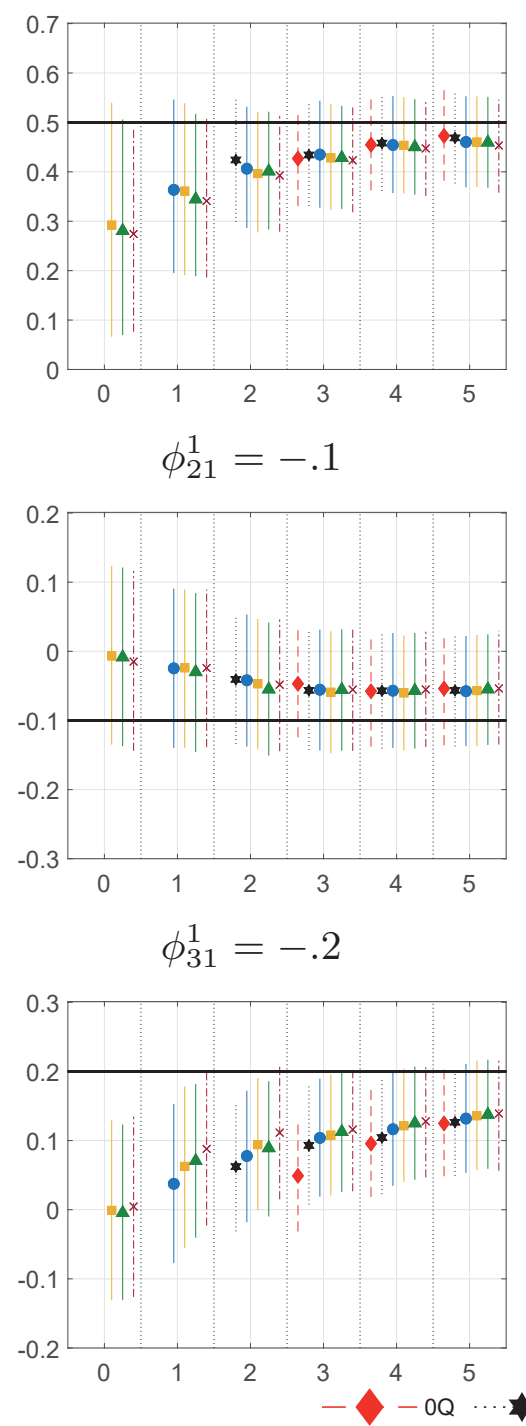

$\phi_{12}^{1}=.3$
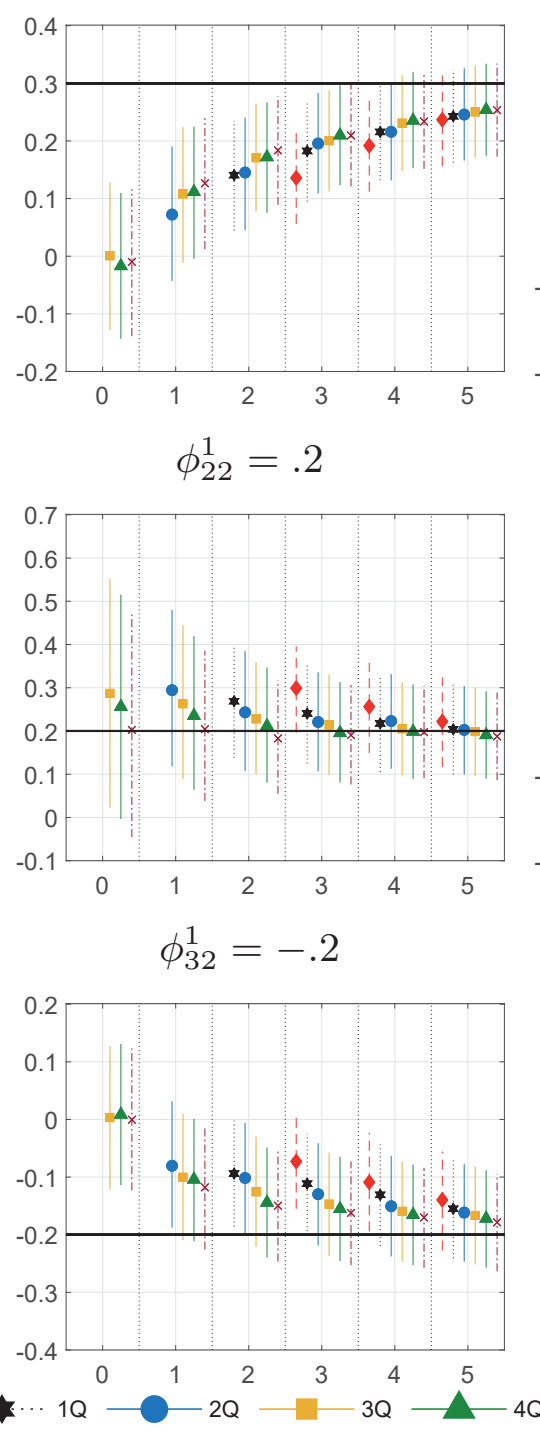

$\phi_{13}^{1}=0$
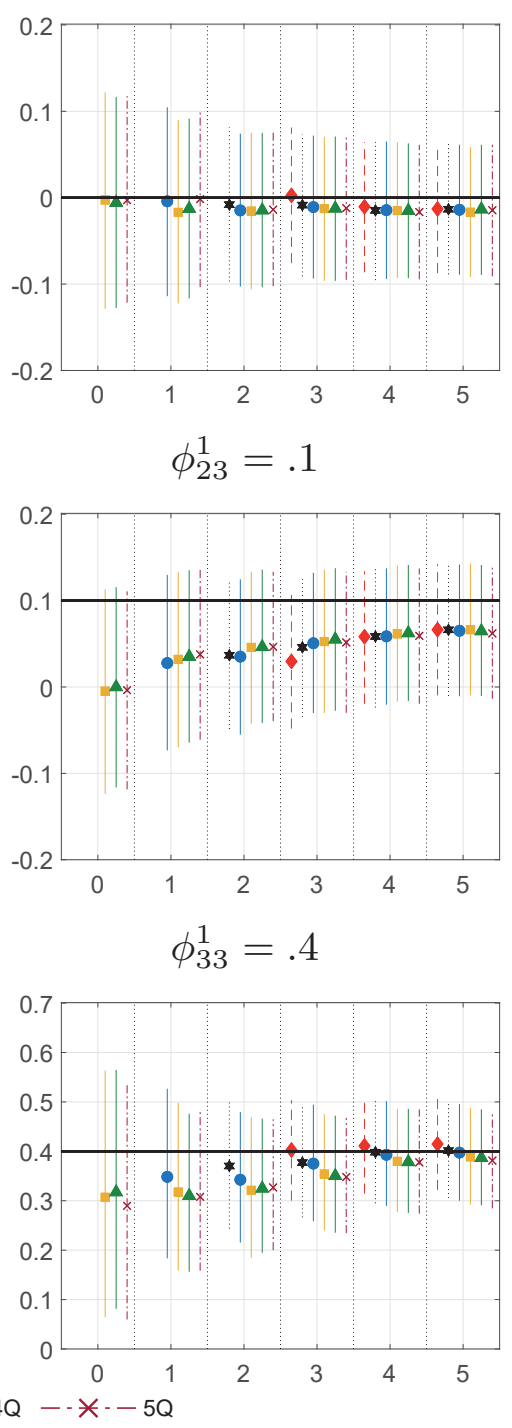

Note: Vertical lines represent the mean of the [16\% - 84\%] quantiles over 100 replications of the estimation of VAR coefficients for each combination of monthly and quarterly variables included per country in the model. The $x$ axes represent the number of monthly variables used in the estimation of each coefficient. The true values of coefficients are shown in titles and with the horizontal black line.

2.2), problems which do not emerge when no spillovers are allowed.

The second result is that for any given number of monthly variables, including more quarterly variables pushes the median value of the VAR parameters to the true values. Adding monthly variables to the estimation also has a positive effect on the estimation of VAR parameters, which is more visible for the parameters of the $\Phi(1)$ matrix. This shows that using mixed frequencies helps in the estimation of factor dynamics, even when quarterly variables are used to infer the dynamics of the monthly unobserved factors. 
Figure 3: Factor VAR coefficients for $\Phi(2)$ :

True values and mean of the $16 \%$ and $84 \%$ estimated quantiles
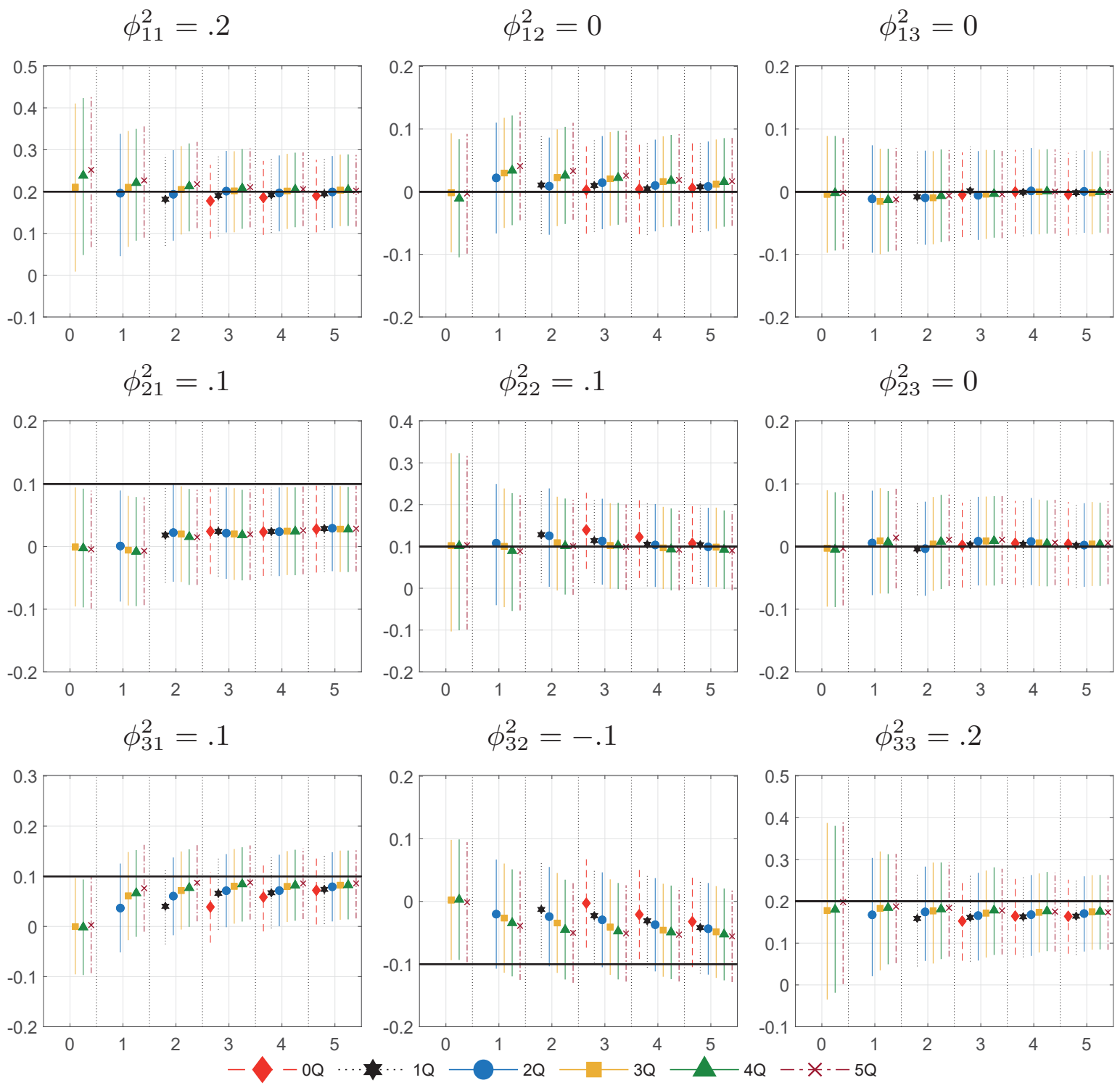

Note: See notes from Figure 2

\section{Empirical Application}

The multilevel dynamic factor model is applied for the G7 economies using a dataset that spans from January 1980 until December 2018.

The empirical application described below has some distinctive features with respect to the literature on multilevel dynamic factor models with a block structure (e.g., Kose et al., 2003 and Crucini et al., 2011, among others). First, our framework allows for the possibility of analyzing the "spillover" effects of shocks originating in any particular country. This is feasible since unobserved factors are allowed to follow an unrestricted $\operatorname{VAR}(p)$ process. Second, by allowing the factors to have a monthly dynamic (through the use of mixed frequencies), we limit the 
possibility that a country innovation generated in a specific month will be confused with a world innovation if it is the case that the country innovation spills over to other economies within a quarter. We further exploit these features, and we analyze how innovations in the GDP growth of one country could affect the expectations of GDP growth in other countries.

\subsection{Data description}

We select the relevant indicators for each country by following Stock and Watson (1989). Apart from GDP, we include one supply-side indicator (industrial production), one demand-side indicator (retail sales), one series describing the employment situation and, when available, one series related to household income. Table 1 shows all series included per country and their respective time spans. Since model estimation does not need a balanced data set, series are not always for the whole period (January 1980-December 2018). All variables are seasonally adjusted and expressed in terms of growth rate to avoid unit root problems. Data are from OECD, national statistical offices, central banks, and Datastream.

\subsection{International business cycles}

The multilevel dynamic factor model described in equations (23), (25), (7), and (6) is estimated for the G7, assuming a $\operatorname{VAR}(2)$ process for the dynamics of the factors and an $\operatorname{AR}(2)$ process for the idiosyncratic errors $u^{i c}$. Sign identification relies on restricting country loading factors associated with the industrial production (IP) of each country and the world loading factor related with this variable (but only for the US) to being strictly positive (i.e., $\beta_{\mathrm{IP}, c}>0$ for $c=1, \ldots, C$ and $\left.\beta_{w}^{\mathrm{IP}, U S}>0\right)$. Scale identification comes from assuming $Q=I_{C+1} \cdot{ }^{14}$

World and country factors are estimated from a Markov Chain of length 8000 (after burning the first 2000 draws). Figure 4 shows the median of the posterior distribution of the estimated world factor, including the $16 \%$ and $84 \%$ percent quantiles. Given the importance the US has for the world economy, the figure also includes NBER recession dates (shaded areas). The figure indicates that the performance of the world economy during NBER recessions has, in general, been negative. In this sense, economic downturns such as the double dip recession of the early 1980s, the mild recession of the early 1990s, the downturn at the end of 2001 (associated with the dot-com bubble burst), and the global financial crisis of 2008 are described by the world factor. Most of these major world economic events were also captured in Aruoba et al. (2011), Kose et al. (2008), Kose et al. (2012), Crucini et al. (2011), and Mumtaz et al. (2011).

Figure 5 shows the evolution of the estimated country-specific factors. Each country captures the economic developments of its respective country. The US country factor exhibits negative

\footnotetext{
${ }^{14}$ Among others, Kose et al. (2003) and Crucini et al. (2011) use similar restrictions. In line with Bai and Wang (2015), the VAR dynamics of the factors remain unrestricted.
} 
Table 1: Data series included per country

\begin{tabular}{|c|c|c|}
\hline & Series & Range \\
\hline United States (US) & $\begin{array}{l}\text { Industrial Production }(\mathrm{m}) \\
\text { Real Manufacturing and Trade Industries Sales }(\mathrm{m}) \\
\text { All Employees: Total Nonfarm Payrolls }(\mathrm{m}) \\
\text { Real Disposable Personal Income }(\mathrm{m}) \\
\text { Real Gross Domestic Product }(\mathrm{Q})\end{array}$ & $\begin{array}{l}\text { 1980:01-2018:12 } \\
\text { 1980:01-2018:12 } \\
\text { 1980:01-2018:12 } \\
\text { 1980:01-2018:12 } \\
\text { 1980:Q1-2018:Q4 }\end{array}$ \\
\hline Japan (JAP) & $\begin{array}{l}\text { Industrial Production }(\mathrm{m}) \\
\text { Total Retail Trade (volume) }(\mathrm{m}) \\
\text { Total Employment (m) } \\
\text { Real Net Household Disposable Income (Q) } \\
\text { Real Gross Domestic Product }(\mathrm{Q})\end{array}$ & $\begin{array}{l}\text { 1980:01-2018:12 } \\
\text { 1980:01-2018:12 } \\
\text { 1980:01-2018:12 } \\
\text { 1980:Q1-2018:Q4 } \\
\text { 1980:Q1-2018:Q4 }\end{array}$ \\
\hline Germany (GER) & $\begin{array}{l}\text { Industrial Production }(\mathrm{m}) \\
\text { Real Trade, except for motor vehicles and motorcycles }(\mathrm{m}) \\
\text { Total Employment }(\mathrm{m}) \\
\text { Real Net Household Disposable Income }(\mathrm{Q}) \\
\text { Real Gross Domestic Product }(\mathrm{Q})\end{array}$ & $\begin{array}{l}\text { 1980:01-2018:12 } \\
\text { 1980:01-2018:12 } \\
\text { 1991:Q1-2018:12 } \\
\text { 1980:Q1-2018:Q4 }\end{array}$ \\
\hline United Kingdom (UK) & $\begin{array}{l}\text { Industrial Production }(\mathrm{m}) \\
\text { Total Retail Trade (volume) }(\mathrm{m}) \\
\text { Total Employment -first period- }(\mathrm{m}) \\
\text { Total Employment -second period- }(\mathrm{m}) \\
\text { Real Household Disposable Income }(\mathrm{Q}) \\
\text { Real Gross Domestic Product }(\mathrm{Q})\end{array}$ & $\begin{array}{l}\text { 1980:01-2018:12 } \\
\text { 1980:01-2018:12 } \\
\text { 1980:01-1991:12 } \\
\text { 1992:01-2018:12 } \\
\text { 1980:Q1-2018:Q4 } \\
\text { 1980:Q1-2018:Q4 }\end{array}$ \\
\hline Canada (CAN) & $\begin{array}{l}\text { Industrial Production (m) } \\
\text { Total Retail Trade (volume) (m) } \\
\text { Total Employment (m) } \\
\text { Real Net Household Disposable Income (Q) } \\
\text { Real Gross Domestic Product (Q) }\end{array}$ & $\begin{array}{l}\text { 1980:01-2018:12 } \\
\text { 1980:01-2018:12 } \\
\text { 1980:01-2018:12 } \\
\text { 1981:Q1-2018:Q4 } \\
\text { 1980:Q1-2018:Q4 }\end{array}$ \\
\hline France (FRA) & $\begin{array}{l}\text { Industrial Production (m) } \\
\text { Household Consumption Expenditure in Manufactured Goods (m) } \\
\text { Payroll Employment (Q) } \\
\text { Real Gross Household Disposable Income (Q) } \\
\text { Real Gross Domestic Product (Q) }\end{array}$ & $\begin{array}{l}\text { 1980:01-2018:12 } \\
\text { 1980:01-2018:12 } \\
\text { 1980:Q1-2017:Q1 } \\
\text { 1980:Q1-2018:Q4 }\end{array}$ \\
\hline Italy (ITA) & $\begin{array}{l}\text { Industrial Production }(\mathrm{m}) \\
\text { Total Retail Trade (volume) -first period- }(\mathrm{m}) \\
\text { Total Retail Trade (volume)-second period- }(\mathrm{m}) \\
\text { Total Employment -all employees excluding executives- }(\mathrm{m}) \\
\text { Real Gross Domestic Product }(\mathrm{Q})\end{array}$ & $\begin{array}{l}\text { 1980:01-2018:12 } \\
\text { 2000:02-2000:01 } \\
\text { 2000:01-2018:12 } \\
\text { 1980:Q1-2018:Q4 }\end{array}$ \\
\hline
\end{tabular}

Note: $(\mathrm{m})$ indicates monthly variables, while $(\mathrm{Q})$ indicates quarterly ones. Data sources are OECD, national statistics offices, Datastream, and national central banks. All series are seasonally adjusted.

Figure 4: World factor

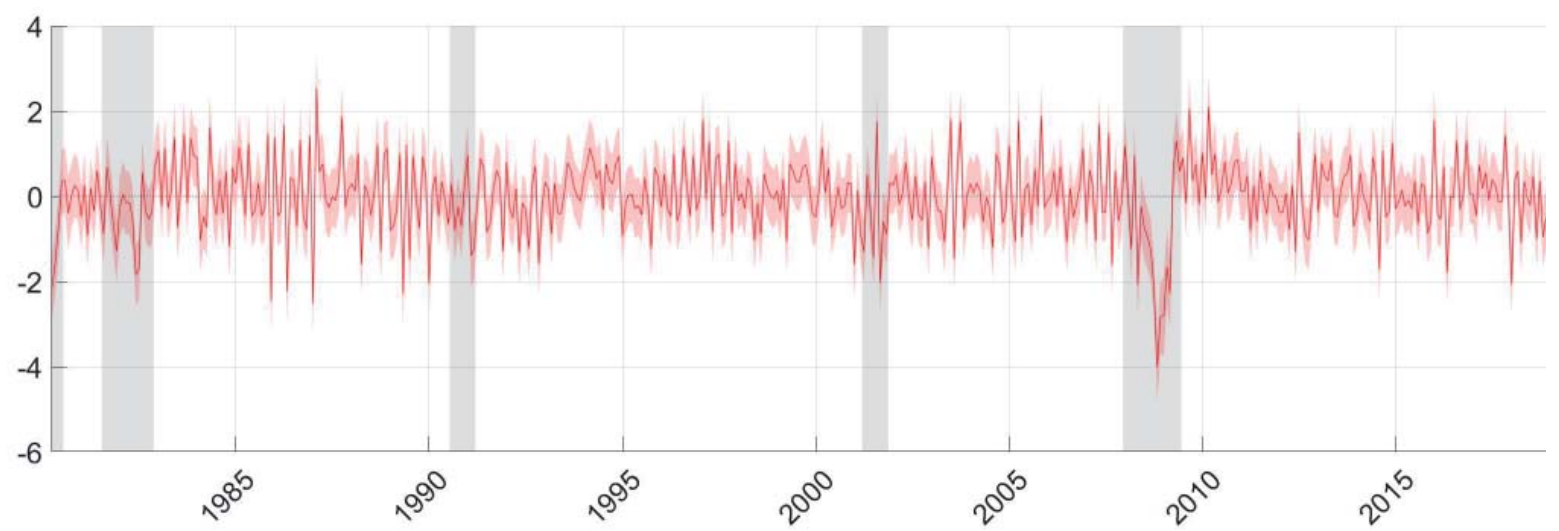

Note: Posterior median and the $16 \%$ and $84 \%$ estimated quantiles. Shaded areas correspond to NBER recession dates.

values during each of the NBER recession dates. The Japanese factor takes negative values for a long period during the 1990s, the "lost decade". The German factor shows the reunification 
boom followed by the recession during the first years of the ' $90 \mathrm{~s}$. The UK factor reflects both the early '80s and '90s recessions. Moreover, factors for European countries also reflect the economic downturn of the "European sovereign debt crisis" in 2011-2012.

In Table 2, we examine how each factor influences national economic cycles. For this purpose, the table reports the relative importance of each factor in the variance of GDP and industrial production. ${ }^{15}$

Figure 5: Country factors
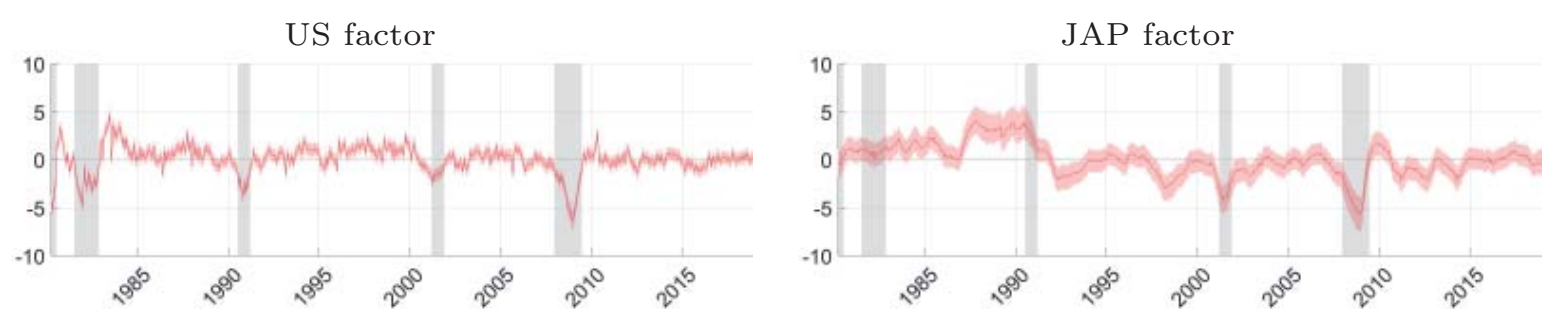

GER factor

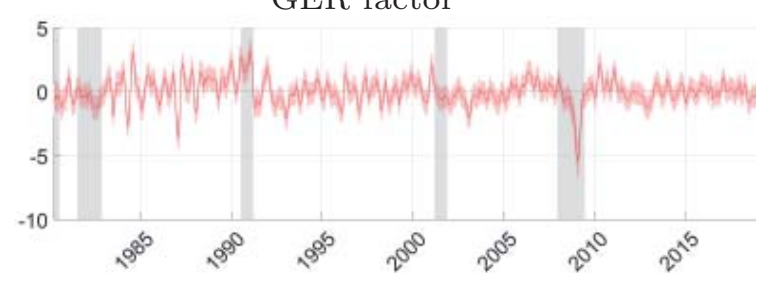

UK factor

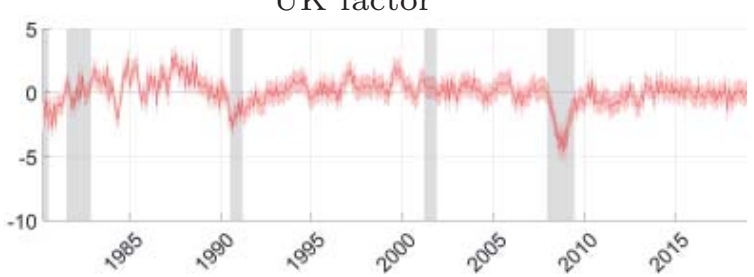

CAN factor
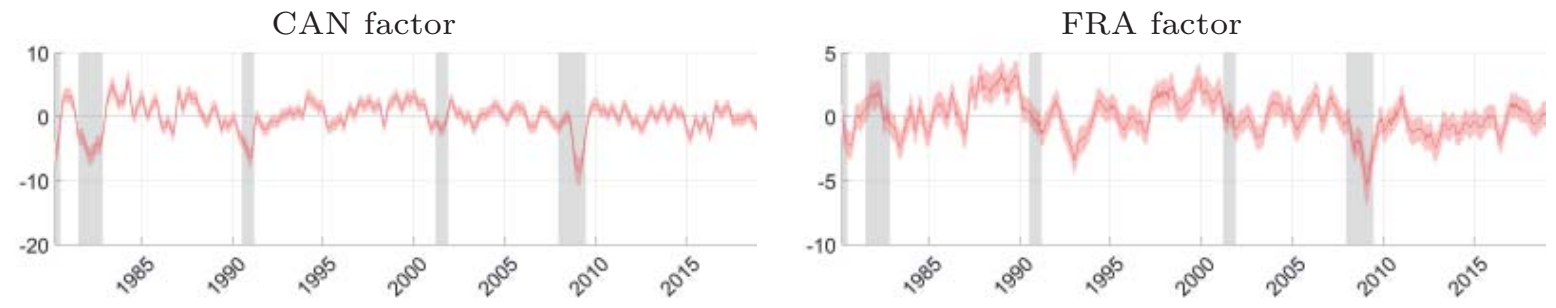

ITA factor

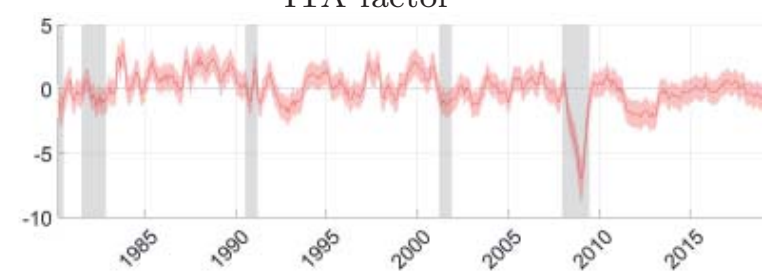

Note: Posterior median and the $16 \%$ and $84 \%$ estimated quantiles. Shaded areas correspond to NBER recession dates.

The table suggests that the share of GDP variability explained by the model is relevant for all G7 economies. The world factor explains a substantial share of the output variance (at least $16 \%$ ) in 5 out of the 7 countries, although its role in explaining the business cycles of Japan and

\footnotetext{
${ }^{15}$ We calculate the variance explained by each factor as if the factors were orthogonal to each other. This is mainly due to difficulties in assigning the magnitudes attributable to the covariance between the factors when calculating the variance share of the non-orthogonal factors. We assume the difference between the share of the variance explained by each factor when the factors are assumed to be orthogonal and when they are assumed to be not, as the magnitudes attributable to that covariance.
} 
Germany appears to be less important. In addition, the country factors explain no less than $24 \%$ of GDP volatility. Finally, although the contribution of world and country-specific factors to the variability of industrial production is also sizable for all countries, the role of the factors in explaining IP cycles diminishes considerably.

Although we find that GDP variance shares explained by the global factor are significant, these shares are lower than those usually obtained in the IBC literature (see Kose et al., 2003, Kose et al., 2008, and Crucini et al., 2011, among many others). The explanation could be that some of the international links are captured in the dynamics of each country factor.

To examine the extent to which allowing for spillovers could explain the lesser role of the

Table 2: Variance decomposition (spillovers are allowed)

\begin{tabular}{|c|c|c|c|c|c|c|c|c|c|c|}
\hline \multirow[b]{2}{*}{ Country } & \multirow[b]{2}{*}{ Variable } & \multicolumn{3}{|c|}{ World } & \multicolumn{3}{|c|}{ Country } & \multicolumn{3}{|c|}{ Idiosyncratic } \\
\hline & & .16 & Med & .84 & .16 & Med & .84 & .16 & Med & .84 \\
\hline US & $\begin{array}{l}\text { GDP } \\
\text { IP }\end{array}$ & $\begin{array}{l}13.8 \\
4.0\end{array}$ & $\begin{array}{c}18.0 \\
5.9\end{array}$ & $\begin{array}{r}22.4 \\
-8.2 \\
-\end{array}$ & $\begin{array}{r}43.6 \\
32.9 \\
-\end{array}$ & $\begin{array}{r}49.5 \\
36.0 \\
\end{array}$ & $\begin{array}{r}55.3 \\
39.2\end{array}$ & $\begin{array}{r}29.2 \\
55.3 \\
-\end{array}$ & $\begin{array}{r}32.5 \\
57.9\end{array}$ & $\begin{array}{r}35.7 \\
60.4\end{array}$ \\
\hline JAP & GDP & $\begin{array}{r}9.2 \\
3.7 \\
\end{array}$ & $\begin{array}{c}13.4 \\
5.7\end{array}$ & $\begin{array}{c}17.9 \\
8.0 \\
-\end{array}$ & $\begin{array}{r}18.5 \\
-1.9 \\
-\end{array}$ & $\begin{array}{c}24.0 \\
-3.0 \\
\end{array}$ & $\begin{array}{c}30.4 \\
4.6\end{array}$ & $\begin{array}{r}57.2 \\
88.6\end{array}$ & $\begin{array}{r}62.2 \\
91.0\end{array}$ & $\begin{array}{r}66.6 \\
93.2\end{array}$ \\
\hline GER & GDP & $\begin{array}{c}4.6 \\
13.0\end{array}$ & $\begin{array}{c}8.9 \\
17.0\end{array}$ & $\begin{array}{l}14.4 \\
21.2\end{array}$ & $\begin{array}{r}71.9 \\
4.2 \\
\end{array}$ & $\begin{array}{r}80.5 \\
6.2 \\
\end{array}$ & $\begin{array}{c}87.0 \\
9.2 \\
\end{array}$ & $\begin{array}{c}6.1 \\
72.1 \\
\end{array}$ & $\begin{array}{c}9.8 \\
76.4\end{array}$ & $\begin{array}{r}15.7 \\
80.2\end{array}$ \\
\hline UK & $\begin{array}{l}\text { GDP } \\
\text { IP }\end{array}$ & $\begin{array}{l}16.4 \\
12.7\end{array}$ & $\begin{array}{l}21.0 \\
15.7\end{array}$ & $\begin{array}{r}26.0 \\
18.9\end{array}$ & $\begin{array}{r}41.4 \\
4.1\end{array}$ & $\begin{array}{r}50.5 \\
-5.9 \\
\end{array}$ & $\begin{array}{c}60.3 \\
7.9 \\
\end{array}$ & $\begin{array}{r}20.1 \\
75.2 \\
\end{array}$ & $\begin{array}{r}28.0 \\
78.3 \\
\end{array}$ & $\begin{array}{r}35.8 \\
81.3\end{array}$ \\
\hline CAN & $\begin{array}{c}\text { GDP } \\
\text { IP }\end{array}$ & $\begin{array}{c}12.3 \\
9.6 \\
\end{array}$ & $\begin{array}{l}16.5 \\
12.8\end{array}$ & $\begin{array}{l}20.8 \\
16.2\end{array}$ & $\begin{array}{r}59.5 \\
14.8 \\
\end{array}$ & $\begin{array}{l}65.4 \\
16.7\end{array}$ & $\begin{array}{l}70.9 \\
18.7\end{array}$ & $\begin{array}{l}14.6 \\
67.5\end{array}$ & $\begin{array}{l}18.1 \\
70.5\end{array}$ & $\begin{array}{r}21.8 \\
73.1\end{array}$ \\
\hline FRA & GDP & $\begin{array}{l}15.0 \\
20.1\end{array}$ & $\begin{array}{r}22.0 \\
24.7\end{array}$ & $\begin{array}{r}30.2 \\
29.8 \\
-\end{array}$ & $\begin{array}{r}54.7 \\
-1.5 \\
\end{array}$ & $\begin{array}{r}65.6 \\
-2.7 \\
\end{array}$ & $\begin{array}{c}73.9 \\
4.3 \\
\end{array}$ & $\begin{array}{r}8.0 \\
67.4 \\
\end{array}$ & $\begin{array}{r}11.7 \\
72.4\end{array}$ & $\begin{array}{l}19.1 \\
76.8\end{array}$ \\
\hline ITA & $\begin{array}{c}\text { GDP } \\
\text { IP }\end{array}$ & $\begin{array}{l}11.2 \\
17.0\end{array}$ & $\begin{array}{l}17.0 \\
20.7\end{array}$ & $\begin{array}{l}23.6 \\
24.7\end{array}$ & $\begin{array}{c}44.8 \\
3.1\end{array}$ & $\begin{array}{c}57.3 \\
4.8\end{array}$ & $\begin{array}{c}69.0 \\
7.0\end{array}$ & $\begin{array}{l}16.3 \\
70.6\end{array}$ & $\begin{array}{l}25.2 \\
74.2\end{array}$ & $\begin{array}{l}34.9 \\
77.5\end{array}$ \\
\hline
\end{tabular}

Note: Medians, $16 \%$ and $84 \%$ quantiles of posterior variance shares.

world factor, we also run the model under the assumption that factors are orthogonal. Table 3, which reports the variance decomposition under orthogonality, evidences a significantly greater role of the world factor, in line with the existing literature. As noticed by Stock and Watson (2005), when all cross-dynamics are attributed to a common shock (factors are orthogonal), it is not possible to separate effects of common shocks from those of spillovers.

\subsection{Spillover effects on factor dynamics}

To analyze the "spillover" effects of shocks affecting any particular country factor or the global component, we plot in Figure 6 the IRFs of the global and each of the three major economies' factors (US, Germany, and Japan) to shocks in the dynamics of the factors. ${ }^{16}$. The posterior

\footnotetext{
${ }^{16}$ The rest of the IRFs are shown in Appendix D
} 
medians are used to denote the point estimates, while the lower and upper $16 \%$ quantiles are adopted as the error bands.

Some noteworthy features emerge from the plotted IRFs. First, shocks to the world factor play a significant role in the dynamics of most of the country factors. The US and the Euroarea countries exhibit the largest reactions to world shocks. Second, the world factor reacts positively to shocks to the country factors of the US, Japan, the UK, and Canada. Third, the US is the only country that generates significantly positive spillovers in all 6 other economies, which confirms the importance the US economic cycle has for the world economy. Fourth, shocks

Table 3: Variance decomposition (spillovers not allowed)

\begin{tabular}{|c|c|c|c|c|c|c|c|c|c|c|}
\hline \multirow[b]{2}{*}{ Country } & \multirow[b]{2}{*}{ Variable } & \multicolumn{3}{|c|}{ World } & \multicolumn{3}{|c|}{ Country } & \multicolumn{3}{|c|}{ Idiosyncratic } \\
\hline & & .16 & Med & .84 & .16 & Med & .84 & .16 & Med & .84 \\
\hline \multirow{2}{*}{ US } & GDP & 19.1 & 21.8 & 24.6 & 39.2 & 43.7 & 48.0 & 31.2 & 34.5 & 37.7 \\
\hline & IP & 5.7 & 7.6 & 9.9 & 32.0 & 35.6 & 39.2 & 53.7 & 56.7 & 59.5 \\
\hline \multirow{2}{*}{ JAP } & GDP & 21.8 & 24.5 & 27.2 & 11.8 & 15.0 & 19.2 & 56.2 & 60.2 & 63.7 \\
\hline & IP & 4.6 & 6.4 & 8.4 & 0.4 & 0.9 & 1.8 & 90.4 & 92.5 & -94.3 \\
\hline \multirow{2}{*}{ GER } & GDP & 32.1 & 35.2 & 38.5 & 48.7 & 53.7 & 58.4 & 7.5 & 10.9 & 15.0 \\
\hline & $\mathrm{IP}_{-}$ & 15.7 & 18.4 & 21.4 & 1.1 & $\mathbf{2 . 7}$ & 5.8 & 74.5 & 78.3 & 81.5 \\
\hline \multirow{2}{*}{ UK } & GDP & 25.9 & 28.9 & 32.0 & 43.7 & 48.7 & 53.2 & 18.8 & 22.4 & 26.4 \\
\hline & IP & 9.9 & 12.1 & 14.6 & 3.6 & 4.8 & 6.2 & 80.5 & 83.0 & 85.2 \\
\hline \multirow{2}{*}{ CAN } & GDP & 17.8 & 20.4 & 23.1 & 57.3 & 61.9 & 66.3 & 14.3 & 17.7 & 21.3 \\
\hline & $\underline{I P}_{-}$ & 9.0 & $\underline{11} .1$ & 13.4 & 13.3 & 15.4 & $\underline{17} .9$ & 70.8 & 73.3 & -75.7 \\
\hline \multirow{2}{*}{ FRA } & GDP & 50.4 & 54.5 & 58.5 & 18.6 & 31.4 & 38.6 & 7.5 & 13.3 & 26.6 \\
\hline & IP & 14.5 & 17.4 & 20.7 & 0.1 & 0.5 & 2.3 & 77.1 & 81.3 & 84.6 \\
\hline \multirow{2}{*}{ ITA } & GDP & 46.4 & 50.0 & 53.8 & 0.0 & 0.5 & 2.1 & 44.9 & 48.9 & 52.8 \\
\hline & IP & 17.0 & 19.9 & 22.8 & 2.6 & 5.2 & 8.4 & 70.6 & 74.7 & 78.4 \\
\hline
\end{tabular}

Note: Medians, $16 \%$ and $84 \%$ quantiles of posterior variance shares.

to the Japanese factor affect only the dynamics of continental European countries, while shocks to the UK factor means positive spillovers for all factors except the Japanese one. In sum, the spillover effects from each of the countries are significant sources of economic co-movements among the G7 countries.

However, the IRFs shown in Figure 6 and 8 have two important drawbacks: (i) the IRF refers to non-observable variables; therefore, even though it could be of interest to conceptually describe the spillover and correlations across countries, they are useless from a policymaker perspective (observable variables are the information available for the policymaker, and they have to make inferences about co-movements across countries based on those observables); (ii) one of the variables included in the VAR is the world factor, which is estimated using data from all countries; therefore, if a change in one major economy affects other countries contemporaneously, the model could interpret it as movements in the world factor (even though they are movements 
that come from that major economy). A deeper analysis that tries to solve this problem is presented in the following subsection.

\subsection{Spillover effects on observables}

The drawbacks we mentioned at the end of the previous subsection do not imply that the underlying model cannot be used to analyze the dynamics of the observable variables. In this section, we examine how these variables react to a surprise in the evolution of their partners'

Figure 6: Impulse response functions
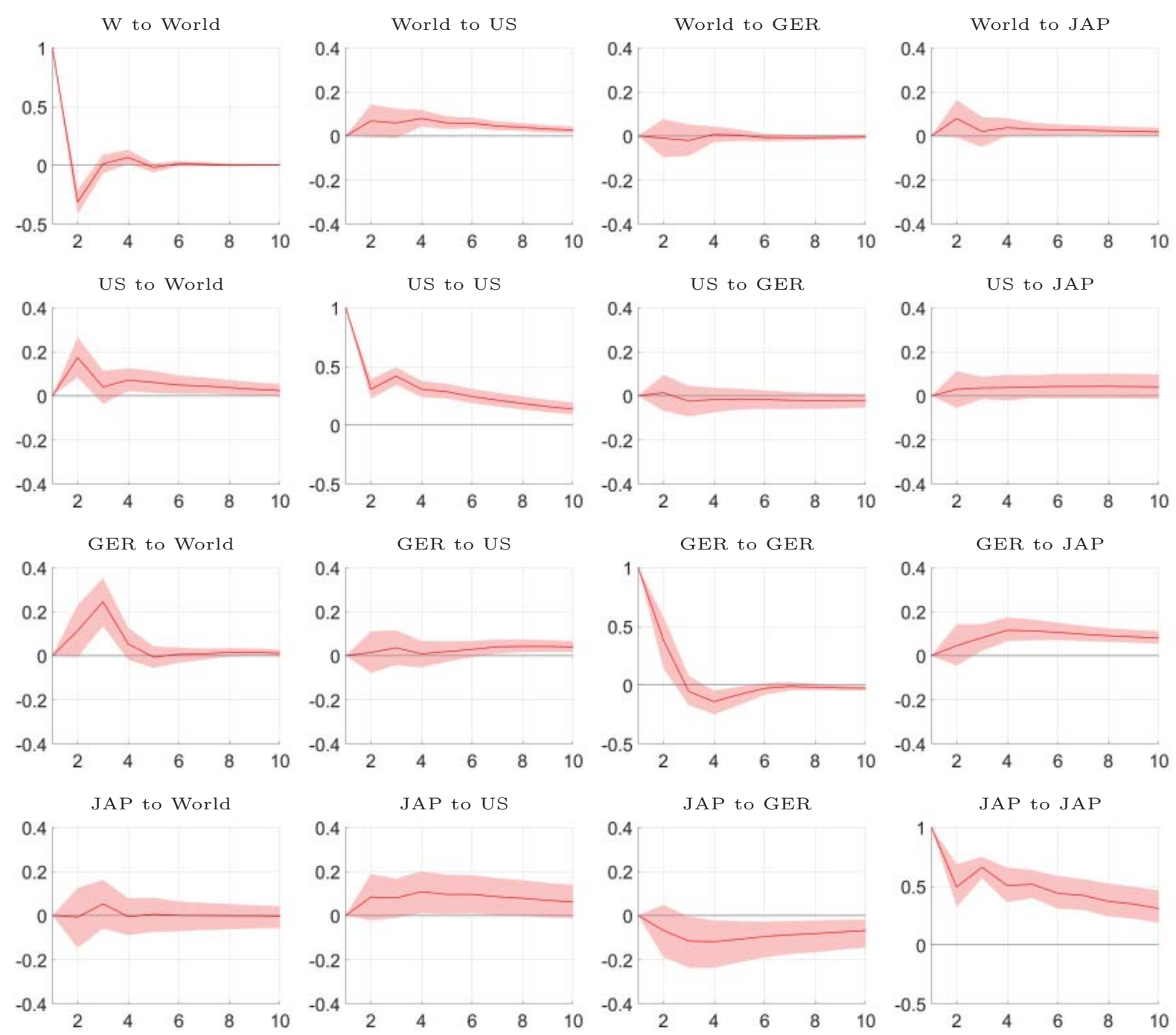

Note: Posterior median and the $16 \%$ and $84 \%$ estimated quantiles. The number of periods after a shock refers to months.

economic variables. In particular, we analyze how national GDP releases affect the forecast of the evolution of GDP in other countries.

For this purpose, we measure the transmission of a surprise in country $j$ 's GDP (the difference between the release and the forecast of the model in country $j$ ) to the conditional forecasts of 
the other countries' GDPs by comparing two different conditional forecast scenarios. In the first scenario, we perform a four-period-ahead forecast (from $T+1$ to $T+4$ ) for each country, under the assumption that no additional shocks hit the economies. In the second scenario, we add a surprise of a size of 0.5 standard deviations at $T+1$ to the GDP of country $j$. The differences approach the revisions of GDP forecasts due to the unexpected change in the GDP of country

Figure 7: One-year cumulative changes in GDP growth in response to 0.5 standard deviations of extra growth in the GDP of each country
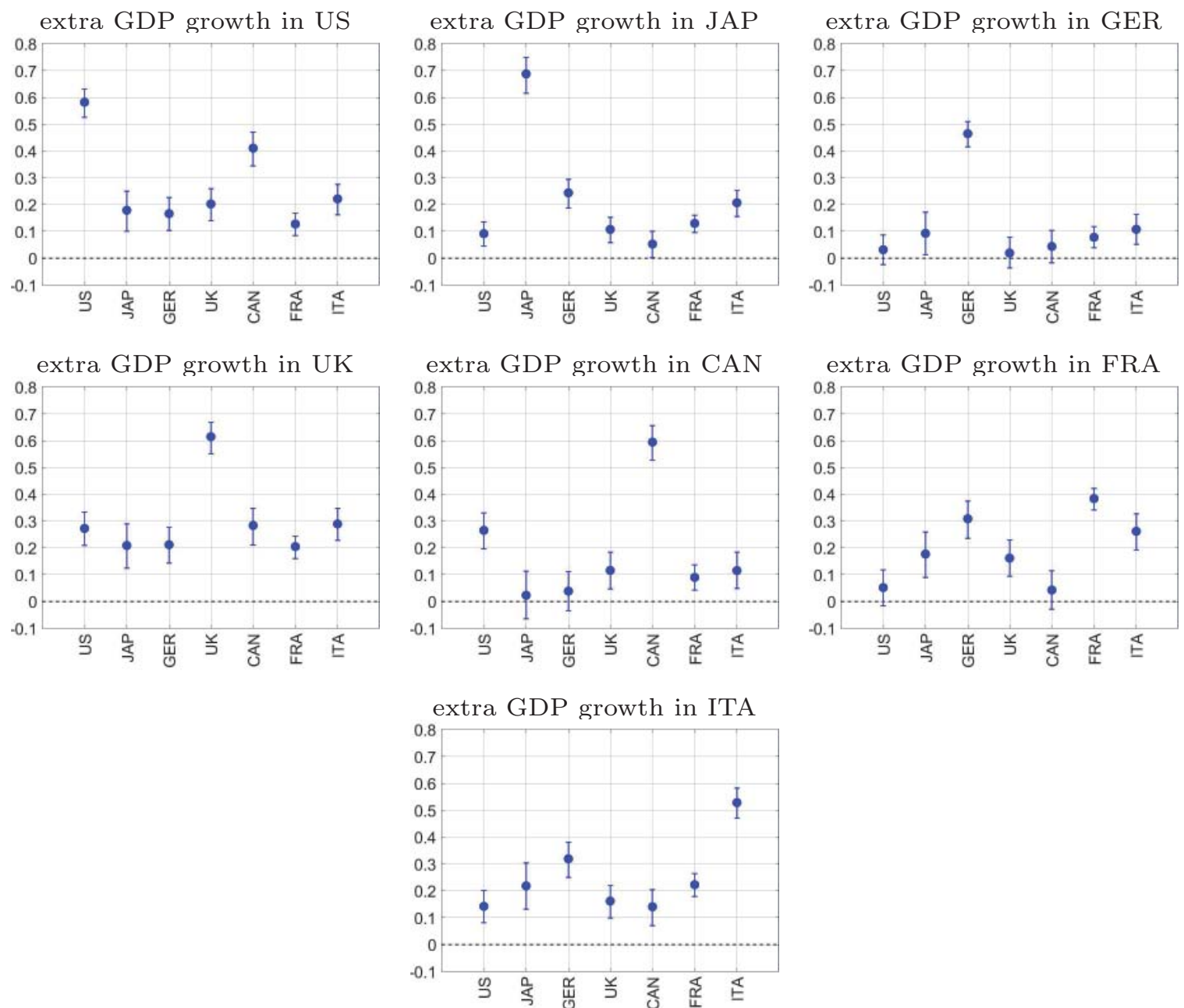

Note: Posterior median and the $16 \%$ and $84 \%$ estimated quantiles. The $y$ axes measure the cumulative growth difference, in percentage points, between a base forecast scenario and a scenario where the GDP forecast of a particular country is increased by half a standard deviation.

$j$.

To estimate conditional forecasts, we follow the conditional forecast algorithm proposed by Banbura et al. (2015). In particular, the exercise is set as follows: we first estimate the onequarter-ahead forecast for each of the variables included in the model. These forecasts are generated conditional on the information set $\mathcal{I}_{T}=\left\{y_{t}^{i c}, i=1, \ldots, N, c=1, \ldots, C, t=1, \ldots, T\right\}$ 
in every draw of the Gibbs sampling and by means of the Kalman filter. The median of all draws is taken as the point forecast $\left(\tilde{y}_{T+1 \mid \mathcal{I}_{T}}^{i}\right)$ and is assumed as given.

The first of the scenarios consists in computing forecasts from $T+1$ to $T+4$ conditional on the estimated GDP point forecast for one of the countries (country " $j$ "). In other words, a new information set given by $\tilde{\mathcal{I}}_{T+1}=\left\{\mathcal{I}_{T}, \tilde{y}_{T+1 \mid \mathcal{I}_{T}}^{j}\right\}$ is used to conduct those conditional forecasts. It should be noted that only $\tilde{y}_{T+1 \mid \mathcal{I}_{T}}^{j}$ is supposed to be known at this step and a new set of forecasts $\tilde{\tilde{y}}_{T+1 \mid \tilde{\mathcal{I}}_{T+1}}^{i}, \forall i \neq j$, which can be generated at each draw of the sampling by means of the simulation-smoother algorithm (assuming $y_{T+1}^{i}, i \neq j$ are missing observations). Forecasts for $T+2$ to $T+4$ are then recursively obtained using the Kalman filter. The second scenario involves assuming a positive surprise in the one-quarter-ahead GDP point estimate forecast of the same country $j$. This scenario is computed as in the first scenario, but adding half a standard deviation to $\tilde{y}_{T+1 \mid \mathcal{I}_{T}}^{j}$.

Some clarification is required regarding the forecast computations. First, the difference between both scenarios is computed as the difference between the forecasts obtained for each scenario at each draw of the sampler. Of course, we use the same seed to start the sampling required to compute the forecasts from both scenarios. Second, we use the same parameter estimates at each iteration of the sampler when generating the two paths of forecasts. Therefore, the parameters used in each of the scenarios are those obtained and saved at each draw of the sampler when running the model conditional only on $\mathcal{I}_{T}$ (i.e., when estimating $\tilde{y}_{T+1 \mid \mathcal{I}_{T}}^{j}$ ). Third, both scenarios are computed seven times, assuming a positive surprise in each of the countries' GDP growth, one at a time.

Summarizing, the exercise is performed as follows:

i. Following the estimation strategy described in Appendix B, draw $\varphi^{(h)}$ conditional on $\mathcal{I}_{T}$ from each posterior distribution, and save each iteration $h$.

ii. Following the estimation strategy described in Subsection 3.1 (iv), draw the latent factors conditional on $\varphi^{(h)}$ and $\mathcal{I}_{T}$ and iterate on the Kalman filter to obtain $y_{T+1 \mid \mathcal{I}_{T}}^{i c(h)}$. Keep the median of all $h$ draws for variable $j$ of country $c\left(\tilde{y}_{T+1 \mid \mathcal{I}_{T}}^{j c}\right)$.

iii. Compute $\tilde{\tilde{y}}_{\left(T+1 \mid \tilde{\mathcal{I}}_{T+1}, \varphi^{(h)}\right)}^{i c(h)}$ for all variables different from variable $j$ of country $c$ by means of

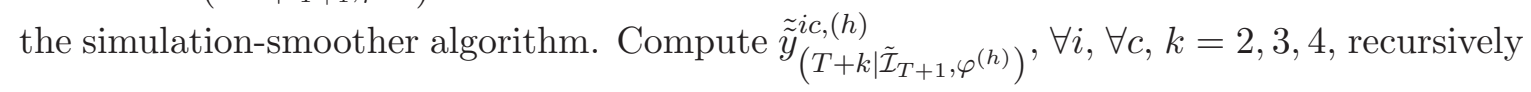
by means of the Kalman filter. Repeat this step but adding half a standard deviation to $\tilde{y}_{T+1 \mid \mathcal{I}_{T}}^{j}$ (scenario two).

iv. Compute the difference between the two scenarios at each iteration $h$.

Figure 7 displays the one-year cumulative difference between the two scenarios for the GDP growth of each of the countries. Some important results can be described. First, positive 
innovations in the GDP of all G7 economies never result in a negative impact on the GDP growth of G7 partners. This means that expectations in G7 countries are positively correlated.

Second, the countries that generate the largest spillovers after positive surprises in the national GDP growth rates are the US and UK. Specifically, half a standard deviation of extra GDP growth in the US and UK could result, after one year, in 0.1-0.4 percentage points of expected extra growth in all other G7 countries. The relevance of the US economic cycle on the rest of the world also appears in Dées and Vansteenkiste (2007) and Bayoumi and Swiston (2009), among many others. Within a structural VAR framework, Poirson-Ward and Weber (2011) document the importance not only of the US but also of the UK in generating spillover effects.

The noticeable impact of the UK on the economic cycles of the other G7 countries has been attributed to two features: (i) the high level of co-movements among the English-speaking G7 countries (examples are Duarte and Holden, 2003, Stock and Watson, 2005, and Camacho and Perez-Quiros, 2006) and (ii) the relatively larger weight of the UK economy as compared to other European Union economies. ${ }^{17}$

Third, we find a small impact of innovations in Germany's GDP growth on the conditional forecasts of the other G7 countries. Poirson-Ward and Weber (2011) also found small spillover effects of German shocks and suggest that countries that are export-oriented generate smaller spillovers than those that rely on domestic sources of growth. However, the conditional forecasts of German GDP show large responses to unexpected changes in other countries' GDP shocks, and particularly those in the Euro area. ${ }^{18}$

Finally, the export-oriented Japanese economy has suffered from the same limitations as Germany in generating positive spillovers. In particular, even though the effects from innovations in Japan's GDP are larger than those found in the case of Germany, they are at the same time smaller than those generated in other countries.

Therefore, policymakers attempting to implement stabilization policies should closely monitor unexpected changes in foreign the output growth of foreign economies.

\section{Conclusions}

Multilevel dynamic factor models are one of the most commonly used frameworks when studying the evolution of international business cycles and the importance of common external shocks for national output fluctuation. However, these models do not account for spillover channels

\footnotetext{
${ }^{17}$ At the moment of writing this article, the UK was starting negotiations to leave the Union.

${ }^{18}$ Bornhorst and Mody (2012) indicate that despite the size of the German economy, its export-oriented growth generates high GDP volatility due to the high volatility of external demand. They argue that this growth structure has limited Germany from generating higher growth in other countries.
} 
across economies. Based on the identification results of Bai and Wang (2015), we eliminate the factor-independence assumption.

In addition, although some business cycle transmissions occur at higher-than-quarterly frequencies, these models omit this information as it would require dealing with data samples at monthly and quarterly frequencies. The model outlined in this paper also handles data at mixed monthly and quarterly frequencies.

We verified that the proposed methodology properly captures common and country-specific co-movements through a Monte Carlo analysis. Within this setup, we also show that the spillovers are well addressed.

Finally, we apply the proposed methodology to examining international spillovers across the G7 economies by analyzing the responses of national factors to shocks in foreign factors and by quantifying the changes in national GDP expectations to unexpected positive changes in foreign GDPs.

Our results are summarized as follows. First, we find that the common-to-all factor represents a relevant share of the output variances. However, its size is smaller than usually found in the literature because a sizable portion of this share is accounted for by the international spillovers. This highlights the importance of the spillover channel as a source of economic co-movement among the G7 economies.

Second, positive shocks to output growth in each of the G7 countries never negatively affects other G7 economies, which agrees with a pro-cyclical channel of international transmission of output growth expectations. In this context, the US and UK generate the largest spillovers while the two export-oriented economies, Japan and Germany, produce the smallest spillovers.

Therefore, policymakers attempting to implement stabilization policies should closely monitor unexpected changes to the output growth of foreign economies. 


\section{References}

Antonakakis, N., I. Chatziantoniou, and G. Filis (2016): "Business Cycle Spillovers in the European Union: What is the Message Transmitted to the Core?" The Manchester School, 84, 437-481.

Aruoba, S. B. And F. X. Diebold (2010): "Real-Time Macroeconomic Monitoring: Real Activity, Inflation, and Interactions," American Economic Review, 100, 20-24.

Aruoba, S. B., F. X. Diebold, M. A. Kose, And M. E. Terrones (2011): "Globalization, the Business Cycle, and Macroeconomic Monitoring," in NBER International Seminar on Macroeconomics, University of Chicago Press, vol. 7, 245-286.

BAI, J. AND P. WANG (2015): "Identification and Bayesian Estimation of Dynamic Factor Models," Journal of Business \& Economic Statistics, 33, 221-240.

Banbura, M., D. Giannone, And M. Lenza (2015): "Conditional forecasts and scenario analysis with vector autoregressions for large cross-sections," International Journal of Forecasting, 31, 739-756.

Bayoumi, T. And A. Swiston (2009): "Foreign Entanglements: Estimating the Source and Size of Spillovers across Industrial Countries," IMF Staff Papers, 56, 353-383.

Blasques, F., S. J. Koopman, M. Mallee, and Z. Zhang (2016): "Weighted maximum likelihood for dynamic factor analysis and forecasting with mixed frequency data," Journal of Econometrics, 193, 405-417.

Bornhorst, F. And A. Mody (2012): "Tests of German Resilience," Tech. rep., International Monetary Fund.

Camacho, M. and G. Perez-Quiros (2006): "A new framework to analyze business cycle synchronization," Contributions to Economic Analysis, 276, 133-149.

(2010): "Introducing the euro-sting: Short-term indicator of euro area growth," Journal of Applied Econometrics, 25, 663-694.

Carstensen, K. and L. Salzmann (2017): "The G7 business cycle in a globalized world," Journal of International Money and Finance, 73, 134-161.

Carter, C. K. And R. Kohn (1994): "On Gibbs sampling for state space models," Biometrika, $81,541-553$.

Chib, S. And E. Greenberg (1994): "Bayes inference in regression models with $\operatorname{ARMA}(p, q)$ errors," Journal of Econometrics, 64, 183-206. 
Crucini, M. J., M. A. Kose, And C. Otrok (2011): "What are the driving forces of international business cycles?" Review of Economic Dynamics, 14, 156-175.

Dées, S. And I. VAnsteenkiste (2007): "The transmission of US cyclical developments to the rest of the world," .

Diebold, F. X. And K. Yilmaz (2015): "Measuring the dynamics of global business cycle connectedness," in Unobserved Components and Time Series Econometric, ed. by S. Koopman and N. Shephard, Oxford University Press, 45-70.

Doz, C., D. Giannone, and L. Reichlin (2012): "A quasi-maximum likelihood approach for large, approximate dynamic factor models," Review of economics and statistics, 94, 10141024 .

Duarte, A. And K. Holden (2003): "The business cycle in the G-7 economies," International Journal of forecasting, 19, 685-700.

Durbin, J. And S. J. Koopman (2001): Time Series Analysis by State Space Methods, Oxford University Press.

- (2002): "A simple and efficient simulation smoother for state space time series analysis," Biometrika, 89, 603-616.

Eraker, B., C. W. J. Chiu, A. T. Foerster, T. B. Kim, and H. D. Seoane (2014): "Bayesian Mixed Frequency VARs," Journal of Financial Econometrics, 13, 698-721.

Foroni, C. And M. Marcellino (2016): "Mixed frequency structural vector auto-regressive models," Journal of the Royal Statistical Society: Series A (Statistics in Society), 179, 403425.

Gregory, A. W., A. C. Head, and J. Raynauld (1997): "Measuring world business cycles," International Economic Review, 677-701.

KARlsson, S. ET AL. (2013): "Forecasting with Bayesian vector autoregressions," Handbook of economic forecasting, 2, 791-897.

Kim, C.-J. AND C. R. NeLson (1999): "State-space models with regime switching: classical and Gibbs-sampling approaches with applications," MIT Press Books, 1.

Koopman, S. J. And M. J. PaCce (2016): "Short-term forecasting of business cycle turning points: a mixed frequency Markov-switching dynamic factor analysis," in 9th ECB Workshop on Forecasting Techniques: Forecast Uncertainty and Macroeconomic Indicators, Frakfurt, Germany. 
Kose, M. A., C. Otrok, and E. Prasad (2012): "Global Business Cycles: Convergence or Decoupling?" International Economic Review, 53, 511-538.

Kose, M. A., C. Otrok, And C. H. Whiteman (2003): "International business cycles: World, region, and country-specific factors," American Economic Review, 1216-1239.

(2008): "Understanding the evolution of world business cycles," Journal of international Economics, 75, 110-130.

Litterman, R. B. (1979): "Techniques of forecasting using vector autoregressions," Working paper, Federal Reserve Bank of Minneapolis.

Mariano, R. S. and Y. Murasawa (2003): "A new coincident index of business cycles based on monthly and quarterly series," Journal of Applied Econometrics, 18, 427-443.

Monfort, A., J.-P. Renne, R. Rueffer, and G. Vitale (2003): "Is Economic Activity in the G7 Synchronized? Common Shocks versus Spillover Effects," CEPR Discussion Papers 4119, C.E.P.R. Discussion Papers.

Mumtaz, H., S. Simonelli, and P. Surico (2011): "International comovements, business cycle and inflation: A historical perspective," Review of Economic Dynamics, 14, 176-198.

Otrok, C. And C. H. Whiteman (1998): "Bayesian Leading Indicators: Measuring and Predicting Economic Conditions in Iowa," International Economic Review, 39, 997-1014.

Poirson-Ward, H. And S. Weber (2011): "Growth Spillover Dynamics From Crisis to Recovery," Tech. rep., International Monetary Fund.

Stock, J. H. And M. W. Watson (1989): "New Indexes of Coincident and Leading Economic Indicators," in NBER Macroeconomics Annual 1989, Volume 4, National Bureau of Economic Research, Inc, NBER Chapters, 351-409.

- (2002): "Forecasting using principal components from a large number of predictors," Journal of the American statistical association, 97, 1167-1179.

(2005): "Understanding changes in international business cycle dynamics," Journal of the European Economic Association, 3, 968-1006. 


\section{A Derivation of VAR process under the stacked approach}

\section{A.1 VAR(1) process with stacked observation (3 monthly variables):}

Under the classical representation, a $\operatorname{VAR}(1)$ process including three variables $\left(x_{\tau}^{m_{1}}, x_{\tau}^{m_{2}}\right.$, and $\left.x_{\tau}^{m_{3}}\right)$ can be written as

$$
\left(\begin{array}{l}
x_{\tau}^{m_{1}} \\
x_{\tau}^{m_{2}} \\
x_{\tau}^{m_{3}}
\end{array}\right)=\left(\begin{array}{lll}
\phi_{11} & \phi_{12} & \phi_{13} \\
\phi_{21} & \phi_{22} & \phi_{23} \\
\phi_{31} & \phi_{32} & \phi_{33}
\end{array}\right)\left(\begin{array}{c}
x_{\tau-1}^{m_{1}} \\
x_{\tau-1}^{m_{2}} \\
x_{\tau-1}^{m_{3}}
\end{array}\right)+\left(\begin{array}{c}
\epsilon_{\tau}^{m_{1}} \\
\epsilon_{\tau}^{m_{2}} \\
\epsilon_{\tau}^{m_{3}}
\end{array}\right),
$$

where

$$
\left(\begin{array}{c}
\epsilon_{\tau}^{m_{1}} \\
\epsilon_{\tau}^{m_{2}} \\
\epsilon_{\tau}^{m_{3}}
\end{array}\right) \sim N I D\left(\left(\begin{array}{l}
0 \\
0 \\
0
\end{array}\right),\left(\begin{array}{ccc}
\sigma_{\epsilon_{1}}^{2} & 0 & \\
0 & \sigma_{\epsilon_{2}}^{2} & 0 \\
0 & 0 & \sigma_{\epsilon_{2}}^{2}
\end{array}\right)\right)
$$

Going from the monthly observations of $x_{\tau}^{m_{1}}, x_{\tau}^{m_{2}}$, and $x_{\tau}^{m_{3}}$ to the stacked quarterly vectors $x_{t}^{q_{1}}$, $x_{t}^{q_{2}}$, and $x_{t}^{q_{3}}$ (now $t$ is the quarterly time index), the $\operatorname{VAR}(1)$ process can be written for $(t, 1)$, $(t, 2)$, and $(t, 3)$ as

$$
\begin{aligned}
(t, 1) & \rightarrow\left\{\begin{array}{l}
\left(\begin{array}{c}
x_{t, 1}^{q_{1}} \\
x_{t, 1}^{q_{2}} \\
x_{t, 1}^{q_{3}}
\end{array}\right)=\left(\begin{array}{lll}
\phi_{11} & \phi_{12} & \phi_{13} \\
\phi_{21} & \phi_{22} & \phi_{23} \\
\phi_{31} & \phi_{32} & \phi_{33}
\end{array}\right)\left(\begin{array}{c}
x_{t-1,3}^{q_{1}} \\
x_{t-1,3}^{q_{2}} \\
x_{t-1,3}^{q_{3}}
\end{array}\right)+\left(\begin{array}{c}
\epsilon_{t, 1}^{q_{1}} \\
\epsilon_{t, 1}^{q_{2}} \\
\epsilon_{t, 1}^{q_{3}}
\end{array}\right), \\
(t, 2) \longrightarrow\left\{\begin{array}{l}
x_{t, 2}^{q_{1}} \\
x_{t, 2}^{q_{2}} \\
x_{t, 2}^{q_{3}}
\end{array}\right)=\left(\begin{array}{lll}
\phi_{11} & \phi_{12} & \phi_{13} \\
\phi_{21} & \phi_{22} & \phi_{23} \\
\phi_{31} & \phi_{32} & \phi_{33}
\end{array}\right)\left(\begin{array}{c}
x_{t, 1}^{q_{1}} \\
x_{t, 1}^{q_{2}} \\
x_{t, 1}^{q_{3}}
\end{array}\right)+\left(\begin{array}{c}
\epsilon_{t, 2}^{q_{1}} \\
\epsilon_{t, 2}^{q_{2}} \\
\epsilon_{t, 2}^{q_{3}}
\end{array}\right), \\
(t, 3) \rightarrow\left\{\begin{array}{l}
x_{t, 3}^{q_{1}} \\
x_{t, 3}^{q_{2}} \\
x_{t, 3}^{q_{3}}
\end{array}\right)=\left(\begin{array}{lll}
\phi_{11} & \phi_{12} & \phi_{13} \\
\phi_{21} & \phi_{22} & \phi_{23} \\
\phi_{31} & \phi_{32} & \phi_{33}
\end{array}\right)\left(\begin{array}{c}
x_{t, 2}^{q_{1}} \\
x_{t, 2}^{q_{2}} \\
x_{t, 2}^{q_{3}}
\end{array}\right)+\left(\begin{array}{c}
\epsilon_{t, 3}^{q_{1}} \\
\epsilon_{t, 3}^{q_{2}} \\
\epsilon_{t, 3}^{q_{3}}
\end{array}\right),
\end{array}\right.
\end{aligned}
$$

where $\epsilon_{t}^{q_{1}}, \epsilon_{t}^{q_{2}}$, and $\epsilon_{t}^{q_{3}}$ are the stacked vectors of the innovation errors. It should be noted that variables from both the second and the third month of the quarter, $(t, 2)$ and $(t, 3)$, could be written in terms of the last month of the previous quarter, $(t-1,3)$. This can be done by substituting $\left(x_{t, 1}^{q_{1}}, x_{t, 1}^{q_{2}}, x_{t, 1}^{q_{3}}\right)^{\prime}$ 'in equation (30) by the first equation and $\left(x_{t, 2}^{q_{1}}, x_{t, 2}^{q_{2}}, x_{t, 2}^{q_{3}}\right)$ ' in equation (31) by the second equation. After some algebra, a VAR(1) process can be written using the stacked vectors $x_{t}^{q_{1}}, x_{t}^{q_{2}}$, and $x_{t}^{q_{3}}$ as

$$
X_{t}^{q}=T X_{t-1}^{q}+R \varepsilon_{t}
$$


with matrices

$$
\begin{aligned}
X_{t}^{q} & =\left(\begin{array}{lllllllll}
x_{t, 1}^{q_{1}} & x_{t, 2}^{q_{1}} & x_{t, 3}^{q_{1}} & x_{t, 1}^{q_{2}} & x_{t, 2}^{q_{2}} & x_{t, 3}^{q_{2}} & x_{t, 1}^{q_{3}} & x_{t, 2}^{q_{3}} & x_{t, 3}^{q_{3}}
\end{array}\right)^{\prime}, \\
\varepsilon_{t} & =\left(\begin{array}{lllllllll}
\epsilon_{t, 1}^{1} & \epsilon_{t, 2}^{1} & \epsilon_{t, 3}^{1} & \epsilon_{t, 1}^{2} & \epsilon_{t, 2}^{2} & \epsilon_{t, 3}^{2} & \epsilon_{t, 1}^{3} & \epsilon_{t, 2}^{3} & \epsilon_{t, 3}^{3}
\end{array}\right)^{\prime},
\end{aligned}
$$

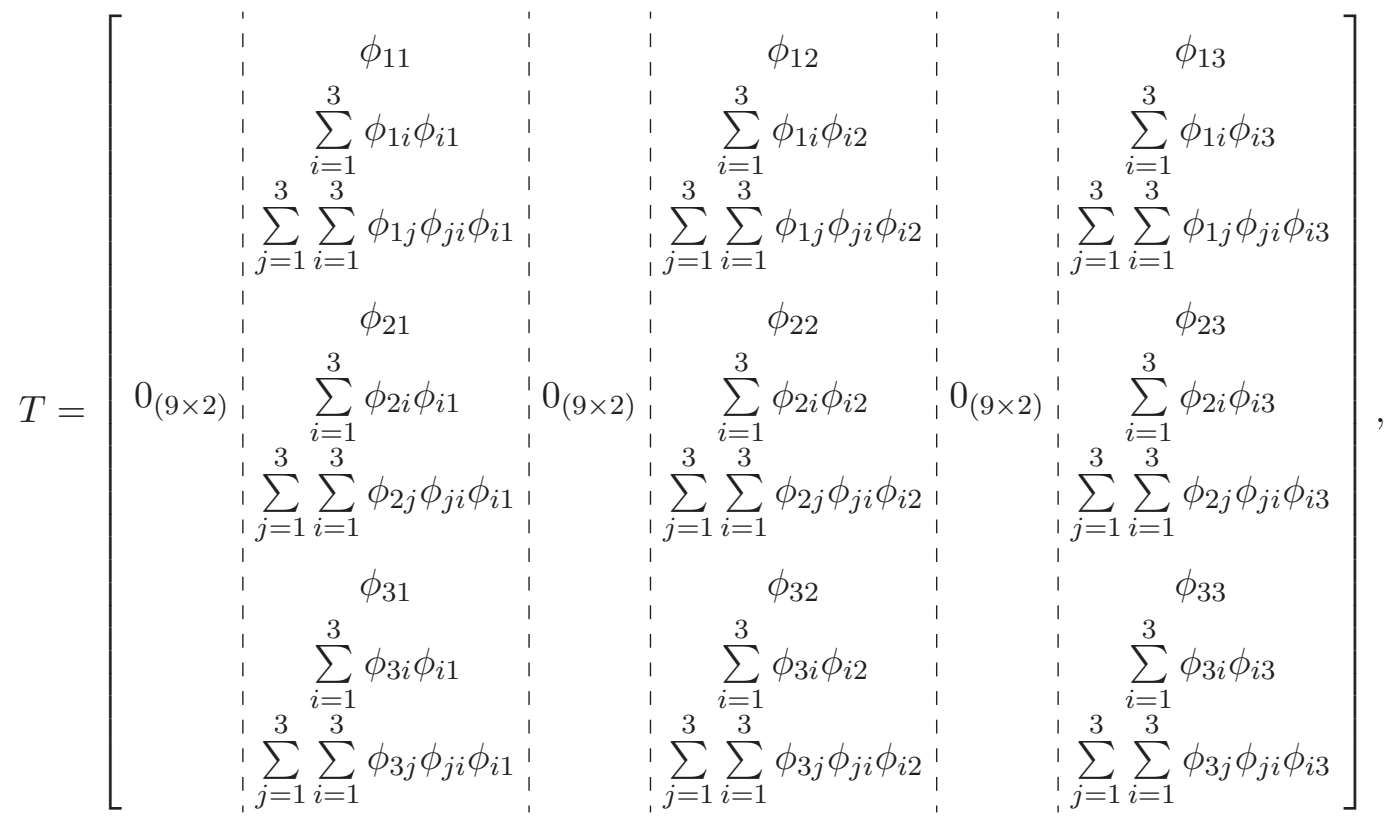

$$
R=\left(\begin{array}{ccccccccc}
1 & 0 & 0 & 0 & 0 & 0 & 0 & 0 & 0 \\
\phi_{11} & 1 & 0 & \phi_{12} & 0 & 0 & \phi_{13} & 0 & 0 \\
\sum_{i=1}^{3} \phi_{1 i} \phi_{i 1} & \phi_{11} & 1 & \sum_{i=1}^{3} \phi_{1 i} \phi_{i 2} & \phi_{12} & 0 & \sum_{i=1}^{3} \phi_{1 i} \phi_{i 3} & \phi_{13} & 0 \\
0 & 0 & 0 & 1 & 0 & 0 & 0 & 0 & 0 \\
\phi_{21} & 0 & 0 & \phi_{22} & 1 & 0 & \phi_{23} & 0 & 0 \\
\sum_{i=1}^{3} \phi_{2 i} \phi_{i 1} & \phi_{21} & 0 & \sum_{i=1}^{3} \phi_{2 i} \phi_{i 2} & \phi_{22} & 1 & \sum_{i=1}^{3} \phi_{2 i} \phi_{i 3} & \phi_{23} & 0 \\
0 & 0 & 0 & 0 & 0 & 0 & 1 & 0 & 0 \\
\phi_{31} & 0 & 0 & \phi_{32} & 0 & 0 & \phi_{33} & 1 & 0 \\
\sum_{i=1}^{3} \phi_{3 i} \phi_{i 1} & \phi_{31} & 0 & \sum_{i=1}^{3} \phi_{3 i} \phi_{i 2} & \phi_{32} & 0 & \sum_{i=1}^{3} \phi_{3 i} \phi_{i 3} & \phi_{33} & 1
\end{array}\right) .
$$

\section{A.2 $\operatorname{VAR}(2)$ process with stacked observation (3 monthly variables):}

Under the classical representation, a VAR(1) process including three variables $\left(x_{\tau}^{m_{1}}, x_{\tau}^{m_{2}}\right.$, and $\left.x_{\tau}^{m_{3}}\right)$ can be written as 


$$
\left(\begin{array}{l}
x_{\tau}^{m_{1}} \\
x_{\tau}^{m_{2}} \\
x_{\tau}^{m_{3}}
\end{array}\right)=\left(\begin{array}{lll}
\phi_{11} & \phi_{12} & \phi_{13} \\
\phi_{21} & \phi_{22} & \phi_{23} \\
\phi_{31} & \phi_{32} & \phi_{33}
\end{array}\right)\left(\begin{array}{c}
x_{\tau-1}^{m_{1}} \\
x_{\tau-1}^{m_{2}} \\
x_{\tau-1}^{m_{3}}
\end{array}\right)+\left(\begin{array}{lll}
\psi_{11} & \psi_{12} & \psi_{13} \\
\psi_{21} & \psi_{22} & \psi_{23} \\
\psi_{31} & \psi_{32} & \psi_{33}
\end{array}\right)\left(\begin{array}{c}
x_{\tau-2}^{m_{1}} \\
x_{\tau-2}^{m_{2}} \\
x_{\tau-2}^{m_{3}}
\end{array}\right)+\left(\begin{array}{c}
\epsilon_{\tau}^{m_{1}} \\
\epsilon_{\tau}^{m_{2}} \\
\epsilon_{\tau}^{m_{3}}
\end{array}\right)
$$

where

$$
\left(\begin{array}{c}
\epsilon_{\tau}^{m_{1}} \\
\epsilon_{\tau}^{m_{2}} \\
\epsilon_{\tau}^{m_{3}}
\end{array}\right) \sim N I D\left(\left(\begin{array}{l}
0 \\
0 \\
0
\end{array}\right),\left(\begin{array}{ccc}
\sigma_{\epsilon_{1}}^{2} & 0 & \\
0 & \sigma_{\epsilon_{2}}^{2} & 0 \\
0 & 0 & \sigma_{\epsilon_{2}}^{2}
\end{array}\right)\right)
$$

Using the same reasoning developed in Appendix A.1 and after some algebra, a VAR(2) process can be written using the stacked vectors $x_{t}^{q_{1}}, x_{t}^{q_{2}}$, and $x_{t}^{q_{3}}$ as

$$
X_{t}^{q}=T X_{t-1}^{q}+R \varepsilon_{t}
$$

with matrices

$$
\begin{aligned}
& X_{t}^{q}=\left(\begin{array}{lllllllll}
x_{t, 1}^{q_{1}} & x_{t, 2}^{q_{1}} & x_{t, 3}^{q_{1}} & x_{t, 1}^{q_{2}} & x_{t, 2}^{q_{2}} & x_{t, 3}^{q_{2}} & x_{t, 1}^{q_{3}} & x_{t, 2}^{q_{3}} & x_{t, 3}^{q_{3}}
\end{array}\right)^{\prime}, \\
& \varepsilon_{t}=\left(\begin{array}{lllllllll}
\epsilon_{t, 1}^{1} & \epsilon_{t, 2}^{1} & \epsilon_{t, 3}^{1} & \epsilon_{t, 1}^{2} & \epsilon_{t, 2}^{2} & \epsilon_{t, 3}^{2} & \epsilon_{t, 1}^{3} & \epsilon_{t, 2}^{3} & \epsilon_{t, 3}^{3}
\end{array}\right)^{\prime}, \\
& T=\left(\begin{array}{llllll}
0_{(9 \times 1)} & T_{1} & 0_{(9 \times 1)} & T_{2} & 0_{(9 \times 1)} & T_{3}
\end{array}\right), \\
& T_{1}=\left(\begin{array}{cc}
\psi_{11} & \phi_{11} \\
\sum_{i=1}^{3} \phi_{1 i} \psi_{i 1} & \sum_{i=1}^{3} \phi_{1 i} \phi_{i 1}+\psi_{11} \\
\sum_{j=1}^{3} \sum_{i=1}^{3} \phi_{1 j} \phi_{j i} \psi_{i 1}+\sum_{i=1}^{3} \psi_{1 i} \psi_{i 1} & \sum_{j=1}^{3} \sum_{i=1}^{3} \phi_{1 j} \phi_{j i} \phi_{i 1}+\sum_{i=1}^{3} \phi_{1 i} \psi_{i 1}+\sum_{i=1}^{3} \phi_{i 1} \psi_{1 i} \\
\psi_{21} & \phi_{21} \\
\sum_{i=1}^{3} \phi_{2 i} \psi_{i 1} & \sum_{i=1}^{3} \phi_{2 i} \phi_{i 1}+\psi_{21} \\
\sum_{j=1}^{3} \sum_{i=1}^{3} \phi_{2 j} \phi_{j i} \psi_{i 1}+\sum_{i=1}^{3} \psi_{2 i} \psi_{i 1} & \sum_{j=1}^{3} \sum_{i=1}^{3} \phi_{2 j} \phi_{j i} \phi_{i 1}+\sum_{i=1}^{3} \phi_{2 i} \psi_{i 1}+\sum_{i=1}^{3} \phi_{i 1} \psi_{2 i} \\
\psi_{31}^{3} \phi_{3 i} \psi_{i 1} & \phi_{31} \\
\sum_{j=1}^{3} \sum_{i=1}^{3} \phi_{3 j} \phi_{j i} \psi_{i 1}+\sum_{i=1}^{3} \psi_{3 i} \psi_{i 1} & \sum_{j=1}^{3} \sum_{i=1}^{3} \phi_{3 j} \phi_{j i} \phi_{i 1}+\sum_{i=1}^{3} \phi_{3 i} \psi_{i 1}+\sum_{i=1}^{3} \phi_{i 1} \psi_{3 i}
\end{array}\right)
\end{aligned}
$$




$$
\begin{aligned}
& T_{2}=\left(\begin{array}{cc}
\psi_{12} & \phi_{12} \\
\sum_{i=1}^{3} \phi_{1 i} \psi_{i 2} & \sum_{i=1}^{3} \phi_{1 i} \phi_{i 2}+\psi_{12} \\
\sum_{j=1}^{3} \sum_{i=1}^{3} \phi_{1 j} \phi_{j i} \psi_{i 2}+\sum_{i=1}^{3} \psi_{1 i} \psi_{i 2} & \sum_{j=1}^{3} \sum_{i=1}^{3} \phi_{1 j} \phi_{j i} \phi_{i 2}+\sum_{i=1}^{3} \phi_{1 i} \psi_{i 2}+\sum_{i=1}^{3} \phi_{i 2} \psi_{1 i} \\
\psi_{22} & \phi_{22} \\
\sum_{i=1}^{3} \phi_{2 i} \psi_{i 2} & \sum_{i=1}^{3} \phi_{2 i} \phi_{i 2}+\psi_{22} \\
\sum_{j=1}^{3} \sum_{i=1}^{3} \phi_{2 j} \phi_{j i} \psi_{i 2}+\sum_{i=1}^{3} \psi_{2 i} \psi_{i 2} & \sum_{j=1}^{3} \sum_{i=1}^{3} \phi_{2 j} \phi_{j i} \phi_{i 2}+\sum_{i=1}^{3} \phi_{2 i} \psi_{i 2}+\sum_{i=1}^{3} \phi_{i 2} \psi_{2 i} \\
\sum_{32}^{3} \phi_{3 i} \psi_{i 2} & \phi_{32} \\
\sum_{j=1}^{3} \sum_{i=1}^{3} \phi_{3 j} \phi_{j i} \psi_{i 2}+\sum_{i=1}^{3} \psi_{3 i} \psi_{i 2} & \sum_{j=1}^{3} \sum_{i=1}^{3} \phi_{3 j} \phi_{j i} \phi_{i 2}+\sum_{i=1}^{3} \phi_{3 i} \psi_{i 2}+\sum_{i=1}^{3} \phi_{i 2} \psi_{3 i}
\end{array}\right), \\
& T_{3}=\left(\begin{array}{cc}
\psi_{13} & \phi_{13} \\
\sum_{i=1}^{3} \phi_{1 i} \psi_{i 3} & \sum_{i=1}^{3} \phi_{1 i} \phi_{i 3}+\psi_{13} \\
\sum_{j=1}^{3} \sum_{i=1}^{3} \phi_{1 j} \phi_{j i} \psi_{i 3}+\sum_{i=1}^{3} \psi_{1 i} \psi_{i 3} & \sum_{j=1}^{3} \sum_{i=1}^{3} \phi_{1 j} \phi_{j i} \phi_{i 3}+\sum_{i=1}^{3} \phi_{1 i} \psi_{i 3}+\sum_{i=1}^{3} \phi_{i 3} \psi_{1 i} \\
\psi_{23} & \phi_{23} \\
\sum_{i=1}^{3} \phi_{2 i} \psi_{i 3} & \sum_{i=1}^{3} \phi_{2 i} \phi_{i 3}+\psi_{23} \\
\sum_{j=1}^{3} \sum_{i=1}^{3} \phi_{2 j} \phi_{j i} \psi_{i 3}+\sum_{i=1}^{3} \psi_{2 i} \psi_{i 3} & \sum_{j=1}^{3} \sum_{i=1}^{3} \phi_{2 j} \phi_{j i} \phi_{i 3}+\sum_{i=1}^{3} \phi_{2 i} \psi_{i 3}+\sum_{i=1}^{3} \phi_{i 3} \psi_{2 i} \\
\psi_{33}^{3} \phi_{3 i} \psi_{i 3} & \phi_{33}^{3} \\
\sum_{j=1}^{3} \sum_{i=1}^{3} \phi_{3 j} \phi_{j i} \psi_{i 3}+\sum_{i=1}^{3} \psi_{3 i} \psi_{i 3} & \sum_{j=1}^{3} \sum_{i=1}^{3} \phi_{3 j} \phi_{j i} \phi_{i 3}+\sum_{i=1}^{3} \phi_{3 i} \psi_{i 3}+\sum_{i=1}^{3} \phi_{i 3} \psi_{3 i}
\end{array}\right), \\
& R=\left(\begin{array}{ccccccccc}
1 & 0 & 0 & 0 & 0 & 0 & 0 & 0 & 0 \\
\phi_{11} & 1 & 0 & \phi_{12} & 0 & 0 & \phi_{13} & 0 & 0 \\
\sum_{i=1}^{3} \phi_{1 i} \phi_{i 1}+\psi_{11} & \phi_{11} & 1 & \sum_{i=1}^{3} \phi_{1 i} \phi_{i 2}+\psi_{12} & \phi_{12} & 0 & \sum_{i=1}^{3} \phi_{1 i} \phi_{i 3}+\psi_{13} & \phi_{13} & 0 \\
0 & 0 & 0 & 1 & 0 & 0 & 0 & 0 & 0 \\
\phi_{21} & 0 & 0 & \phi_{22} & 1 & 0 & \phi_{23} & 0 & 0 \\
\sum_{i=1}^{3} \phi_{2 i} \phi_{i 1}+\psi_{21} & \phi_{21} & 0 & \sum_{i=1}^{3} \phi_{2 i} \phi_{i 2}+\psi_{22} & \phi_{22} & 1 & \sum_{i=1}^{3} \phi_{2 i} \phi_{i 3}+\psi_{23} & \phi_{23} & 0 \\
0 & 0 & 0 & 0 & 0 & 0 & 1 & 0 & 0 \\
\sum_{i=1}^{3} \phi_{3 i} \phi_{i 1}+\psi_{31} & \phi_{31} & 0 & \sum_{i=1}^{3} \phi_{3 i} \phi_{i 2}+\psi_{32} & \phi_{32} & 0 & \sum_{i=1}^{3} \phi_{3 i} \phi_{i 3}+\psi_{33} & \phi_{33} & 1
\end{array}\right) .
\end{aligned}
$$




\section{B Sampling parameters given the factors}

\section{B.1 Loading factors}

The dynamics of monthly variables are given by (1) and (2). As noted in Kose et al. (2003), if we know the true factors, each monthly variable equation can be evaluated as an independent regression with Gaussian autoregressive errors. Thus, one possibility would simply be to estimate the factor loadings as if the latent factors and the remaining parameters were known. Relying on Chib and Greenberg's (1994) Bayesian procedure, which deals with $\operatorname{AR}(p)$ errors, we start by pre-multiplying both sides of equation $(1)$ by $\left(1-\Phi^{i c}(L)\right)$, where $\Phi^{i c}(L)=\phi_{1}^{i c} L-\ldots-\phi_{p_{i}}^{i c} L^{p_{i}}$ and $L$ is a lag operator, in order to write the following quasi-differentiated equation:

$$
\tilde{y}_{\tau}^{i c}=\left(\begin{array}{ll}
\beta_{w}^{i c} & \beta^{i c}
\end{array}\right) \tilde{\mathbf{F}}_{\tau}^{i c}+\varepsilon_{\tau}^{i c}
$$

where the autoregressive part of the residuals disappears and

$$
\begin{gathered}
\tilde{y}_{\tau}^{i c}=\left(1-\phi_{1}^{i c} L-\ldots-\phi_{p_{i}}^{i c} L^{p_{i}}\right) y_{\tau}^{i c} \\
\tilde{\mathbf{F}}_{\tau}^{i c}=\left(1-\phi_{1}^{i c} L-\ldots-\phi_{p_{i}}^{i c} L^{p_{i}}\right)\left[\begin{array}{ll}
F_{\tau}^{w} & f_{\tau}^{c}
\end{array}\right]^{\prime} .
\end{gathered}
$$

Note that $\tilde{\mathbf{F}}_{\tau}^{i c}$ need the superscript $i$ since autoregressive coefficients depend on each of the variables. Under this setting, it is possible to choose for the loading $\mathbf{b}^{i c}=\left[\begin{array}{ll}\beta_{w}^{i c} & \beta^{i c}\end{array}\right]^{\prime}$ the usual normal density priors $p\left(\mathbf{b}^{i c}\right) \sim N\left(\overline{\mathbf{b}^{i c}}, \overline{B^{i c}}\right)$, resulting in the following conditional posterior, which is also normal:

where

$$
p\left(\mathbf{b}^{i c} \mid F^{w}, f^{c}, \varphi_{-\mathbf{b}^{i c}}\right) \sim N\left(\underline{\mathbf{b}^{i c}}, \underline{B^{i c}}\right),
$$

$$
\begin{aligned}
& \underline{B^{i c}}=\overline{B^{i c}}-1+\sigma_{\varepsilon^{i c}}^{-2} \sum_{\tau=1}^{3 T} \tilde{\mathbf{F}}_{\tau}^{i c \prime} \tilde{\mathbf{F}}_{\tau}^{i c}, \\
& \underline{\mathbf{b}^{i c}}=\underline{B^{i c}-1}\left(\overline{B^{i c}}-1 \overline{\mathbf{b}^{i c}}+\sigma_{\varepsilon^{i c}}^{-2} \sum_{\tau=1}^{3 T} \tilde{\mathbf{F}}_{\tau}^{i c \prime} \tilde{y}_{\tau}^{i c}\right) .
\end{aligned}
$$

The case of quarterly variables is slightly harder to deal with since it is equation (25) that needs to be quasi-differentiated. It should be noted that now variables are expressed using the stacked representation for factors with time index $t$. After pre-multiplying both sides of (25) by $\left(1-\Phi_{p}^{i c}(L)\right)$, it is possible to write

$$
\tilde{x}_{t}^{i c}=\left(\begin{array}{ll}
\beta_{w}^{i c} & \beta^{i c}
\end{array}\right) \tilde{\mathbb{F}}_{t}^{i c}+\eta_{t}^{i c},
$$




$$
\begin{aligned}
& \tilde{x}_{t}^{i c}=\left(1-\phi_{1}^{i c} L-\ldots-\phi_{p_{i}}^{i c} L^{p_{i}}\right) x_{t}^{i c},
\end{aligned}
$$

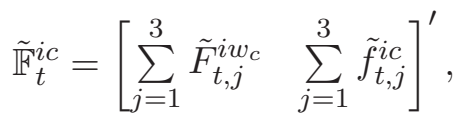

$$
\begin{aligned}
& \left.\begin{array}{rl}
\tilde{F}_{t, j}^{i w_{c}} & =\left(1-\phi_{1}^{i c} L-\ldots-\phi_{p_{i}}^{i c} L^{p_{i}}\right) F_{t, j}^{w} \\
\tilde{f}_{t, j}^{i c} & =\left(1-\phi_{1}^{i c} L-\ldots-\phi_{p_{i}}^{i c} L^{p_{i}}\right) f_{t, j}^{c}
\end{array}\right\} \quad \text { for } \quad j=1,2,3 .
\end{aligned}
$$

Note that the lag operator acts over the time index $t$ (i.e., $L X_{t, j}=X_{t-1, j}$ ). The same kinds of priors as the ones used for the loading factors of monthly variables can be adopted just substituting the quasi-differentiated variables $\left(\tilde{\mathbf{F}}_{\tau}^{i c}, \tilde{y}_{\tau}^{i c}\right)$ by $\left(\tilde{\mathbb{F}}_{t}^{i c}, \tilde{x}_{t}^{i c}\right)$ in $(33)$ and $(34) .{ }^{19}$

\section{B.2 Autoregressive coefficients and innovation variances for observables}

Drawing the autoregressive coefficients for the idiosyncratic components described in equation $(2), \Phi^{i c}=\left(\begin{array}{lll}\phi_{1}^{i c} & \ldots & \phi_{p_{i}}^{i c}\end{array}\right)^{\prime}$, does not involve any particular problem once the idiosyncratic part $\left(u_{t}^{i c}\right)$ and the innovation variance $\sigma_{\varepsilon^{i c}}^{2}$ are treated as if they were known. ${ }^{20}$ Again, following Chib and Greenberg (1994), it is possible to posit the usual conjugate prior density $p\left(\Phi^{i c}\right) \sim$ $N\left(\bar{\Phi}^{i c}, \bar{V}^{i c-1}\right) I_{s \phi}$, where $I_{s \phi}$ is an indicator function for stationarity, and sample from the posterior distribution of $\Phi^{i c}$ using a Metropolis-Hastings algorithm.

Conditional on the AR coefficients, the factor loadings, and the latent factors, the estimation of the innovation variances, $\left(\sigma_{\varepsilon^{i c}}^{2}\right.$ and $\left.\sigma_{\eta^{i c}}^{2}\right)$, is straightforward. Setting the following inverse gamma density prior,

$$
p\left(\sigma_{\varepsilon^{i c}}^{2} \stackrel{d}{=} p\left(\sigma_{\eta^{i c}}^{2}\right) \sim I G\left(\frac{\bar{v}}{2}, \frac{\bar{\delta}}{2}\right)\right.
$$

the conditional posterior distributions are

$$
\begin{aligned}
p\left(\sigma_{\varepsilon^{i c}}^{2} \mid F^{w}, f^{c}, \varphi_{-\sigma_{\varepsilon^{i c}}^{2}}\right) & \sim I G\left(\frac{\bar{v}+3 T}{2}, \frac{\bar{\delta}+\breve{\varepsilon}^{i c}}{2}\right), \\
p\left(\sigma_{\eta^{i c}}^{2} \mid F^{w}, f^{c}, \varphi_{-\sigma_{\varepsilon^{i c}}^{2}}\right) & \sim I G\left(\frac{\bar{v}+T}{2}, \frac{\bar{\delta}+\breve{\eta}^{i c}}{2}\right),
\end{aligned}
$$

where

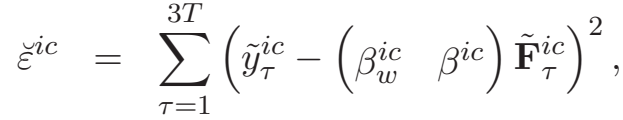

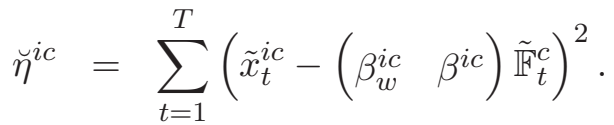

\footnotetext{
${ }^{19}$ Note the summation in both (33) and (34) is now from $t$ to $T$

${ }^{20}$ Otrok and Whiteman (1998) give an excellent and detailed explanation for the AR and the innovation variances parameter sampling.
} 


\section{B.3 VAR coefficients conditional on factors}

Once the world and country factors are assumed as given, the estimation of the VAR process that describes the dynamics of those factors is straightforward. Taking advantage of Bai and Wang's (2015) matrices notation, a $\operatorname{VAR}(p)$ generalization of equation (7) can be written $\mathrm{as}^{21}$

$$
G=H A+\xi \quad \text { or } \quad \operatorname{vec}(G)=\left(I_{(1+C)} \otimes H\right) \alpha+\operatorname{vec}(\xi)
$$

where $\operatorname{vec}(\xi) \sim N\left(0, Q \otimes I_{(3 T-p)}\right)$ and

$$
\begin{gathered}
G=\left[\begin{array}{c}
\mathbf{F}_{(p+1)}^{\prime} \\
\vdots \\
\mathbf{F}_{3 T}^{\prime}
\end{array}\right] \quad, \quad H=\left[\begin{array}{ccc}
\mathbf{F}_{p}^{\prime} & \ldots & \mathbf{F}_{1}^{\prime} \\
\vdots & \ddots & \vdots \\
\mathbf{F}_{(3 T-1)}^{\prime} & \ldots & \mathbf{F}_{(3 T-p)}^{\prime}
\end{array}\right], \\
A=\left[\begin{array}{c}
\Phi(1)^{\prime} \\
\vdots \\
\Phi(p)^{\prime}
\end{array}\right] \quad, \quad \xi=\left[\begin{array}{c}
\xi_{p+1}^{\prime} \\
\vdots \\
\xi_{3 T}^{\prime}
\end{array}\right] \quad, \quad \alpha=\operatorname{vec}(A) .
\end{gathered}
$$

$\mathbf{F}_{\tau}, \Phi(k)$, and $\xi_{\tau}$ were already defined in equation (7). As was mentioned, for identification reasons, the variance-covariance matrix for factor innovations is assumed to be known and diagonal $\left(Q=I_{C+1}\right)$. Therefore, it is feasible to set a normal density prior, $p(\alpha) \sim N\left(\bar{\alpha}, \bar{\Lambda}^{-1}\right)$, with a normal conditional posterior, as

$$
p(\alpha \mid Q, G) \sim N\left(\underline{\alpha}, \underline{\Lambda}^{-1}\right) I_{s \alpha},
$$

where $I_{s \alpha}$ is an indicator function for stationarity and

$$
\begin{aligned}
& \underline{\Lambda}=\bar{\Lambda}^{-1}+Q^{-1} \otimes\left(H^{\prime} H\right), \\
& \underline{\alpha}=\underline{\Lambda}^{-1}\left(\bar{\Lambda}^{-1} \bar{\alpha}+\left(Q^{-1} \otimes H\right) \operatorname{vec}(G)\right) .
\end{aligned}
$$

\section{Starting and prior values}

We follow Crucini et al. (2011) and set priors for all factor loading coefficients as $N(0,10)$, while the autoregressive polynomial parameter's prior is $N\left(0, \Sigma_{i}\right)$, where $\Sigma_{i}=\operatorname{diag}\left((.5)^{0},(.5)^{1}, \ldots,(.5)^{\left(p_{i}-1\right)}\right)$. As explained in Kose et al. (2003), this kind of prior embodies the notion of no serial correlation

\footnotetext{
${ }^{21}$ Note that in order to study the dynamics of the factors, we don't need the stacked representation as it is possible to work using a monthly time frequency.
} 
in the growth rates. The prior of the variances is quite diffuse, being $I G(6,0.001)$. Regarding the prior for the VAR coefficients, we use a variation of a Minnesota prior (Litterman, 1979), centered on the assumption that each factor follows an independent stationary process. ${ }^{22}$

Naming each value of the column vector $\alpha$ (described in 37) as $\alpha_{i j}^{(k)}$, where the subscript and the superscript correspond to those of $\phi_{(k)}^{i j}(k=1, \ldots, p)$, the VAR coefficients are assumed to have the following prior moments:

$$
\bar{\alpha}_{i j}^{(k)}=\left\{\begin{array}{cl}
0.4 & i=j, k=1 \text { (first own lag, }) \\
0.2 & i=j, k=2 \text { (second own lag, }) \\
0 & \text { otherwise }
\end{array}\right.
$$

while $\bar{\Lambda}$ is diagonal and the $\sigma_{i j}^{(k)}$ element corresponding to $\alpha_{i j}^{(k)}$ has the form

$$
\sigma_{i j}^{(k)}= \begin{cases}\frac{\lambda_{0}}{k} & \text { if } i=j, \forall k, \\ \frac{\lambda_{0} \lambda_{1}}{k}\left(\frac{\sigma_{\epsilon_{j}}}{\sigma_{\epsilon_{i}}}\right)^{2} & \text { if } i \neq j, \forall k\end{cases}
$$

where $\lambda_{0}=\lambda_{1}=0.15$. It should also be noted that $\left(\frac{\sigma_{\epsilon_{j}}}{\sigma_{\epsilon_{i}}}\right)^{2}=1$ given that $Q=I_{(C+1)}$.

Stating values for factors come from an $N(0,1)$ distribution. Using those factor values, loading factors and variance starting values result from computing the OLS regression of equations (23) and (25), depending on whether the variable is quarterly or monthly. For the VAR process, values for the main diagonal of $\Phi(1)$ and $\Phi(2)$ are set, respectively, at 0.4 and 0.2 , while all off-diagonal values and autoregressive parameters for innovation errors are set to zero.

\footnotetext{
${ }^{22}$ As indicated in Karlsson et al. (2013), the Minnesota prior uses independent normal distribution for each regression coefficient on the lags, which is appropriate when $Q$ is diagonal. The author also remarks that for computational reasons, this kind of prior takes the error variance to be known (although data-based), which is a valid assumption in our case, given the identification scheme $\left(Q=I_{C+1}\right)$
} 


\section{Impulse response functions}

Figure 8: Impulse Response Functions (3)

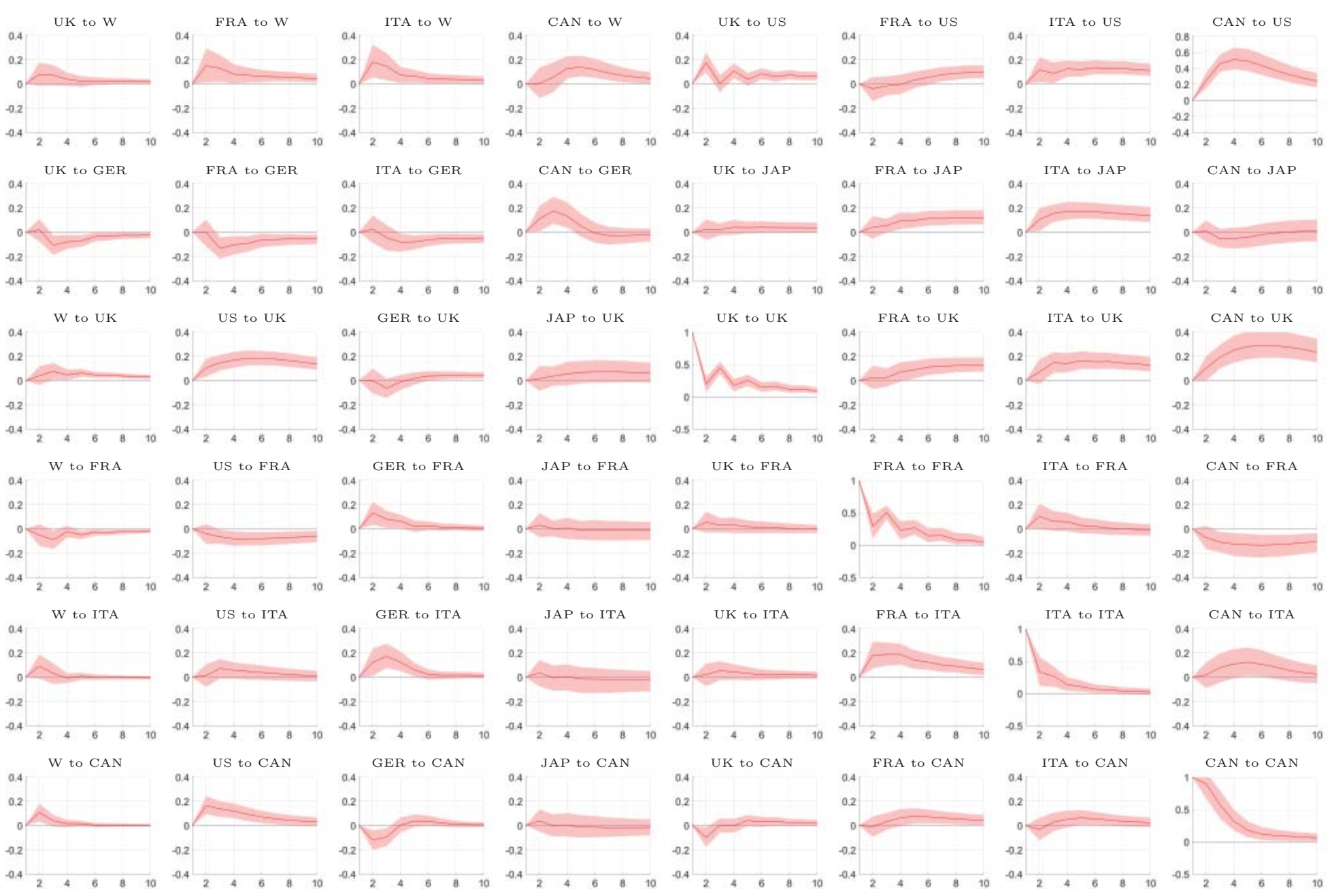

Note: Posterior median and the $16 \%$ and $84 \%$ estimated quantiles. The number of periods after a shock refers to months. 


\section{BANCO DE ESPAÑA PUBLICATIONS}

\section{WORKING PAPERS}

1930 MICHAEL FUNKE, DANILO LEIVA-LEON and ANDREW TSANG: Mapping China's time-varying house price landscape.

1931 JORGE E. GALÁN and MATÍAS LAMAS: Beyond the LTV ratio: new macroprudential lessons from Spain.

1932 JACOPO TIMINI: Staying dry on Spanish wine: the rejection of the 1905 Spanish-Italian trade agreement.

1933 TERESA SASTRE and LAURA HERAS RECUERO: Domestic and foreign investment in advanced economies. The role of industry integration.

1934 DANILO LEIVA-LEON, JAIME MARTÍNEZ-MARTÍN and EVA ORTEGA: Exchange rate shocks and inflation comovement in the euro area.

1935 FEDERICO TAGLIATI: Child labor under cash and in-kind transfers: evidence from rural Mexico.

1936 ALBERTO FUERTES: External adjustment with a common currency: the case of the euro area.

1937 LAURA HERAS RECUERO and ROBERTO PASCUAL GONZÁLEZ: Economic growth, institutional quality and financial development in middle-income countries.

1938 SILVIA ALBRIZIO, SANGYUP CHOI, DAVIDE FURCERI and CHANSIK YOON: International Bank Lending Channel of Monetary Policy.

1939 MAR DELGADO-TÉLLEZ, ENRIQUE MORAL-BENITO and JAVIER J. PÉREZ: Outsourcing and public expenditure: an aggregate perspective with regional data.

1940 MYROSLAV PIDKUYKO: Heterogeneous spillovers of housing credit policy.

1941 LAURA ÁLVAREZ ROMÁN and MIGUEL GARCÍA-POSADA GÓMEZ: Modelling regional housing prices in Spain.

1942 STÉPHANE DÉES and ALESSANDRO GALESI: The Global Financial Cycle and US monetary policy in an interconnected world

1943 ANDRÉS EROSA and BEATRIZ GONZÁLEZ: Taxation and the life cycle of firms.

1944 MARIO ALLOZA, JESÚS GONZALO and CARLOS SANZ: Dynamic effects of persistent shocks.

1945 PABLO DE ANDRÉS, RICARDO GIMENO and RUTH MATEOS DE CABO: The gender gap in bank credit access.

1946 IRMA ALONSO and LUIS MOLINA: The SHERLOC: an EWS-based index of vulnerability for emerging economies

1947 GERGELY GANICS, BARBARA ROSSI and TATEVIK SEKHPOSYAN: From Fixed-event to Fixed-horizon Density Forecasts: Obtaining Measures of Multi-horizon Uncertainty from Survey Density Forecasts.

1948 GERGELY GANICS and FLORENS ODENDAHL: Bayesian VAR Forecasts, Survey Information and Structural Change in the Euro Area.

2001 JAVIER ANDRÉS, PABLO BURRIEL and WENYI SHEN: Debt sustainability and fiscal space in a heterogeneous Monetary Union: normal times vs the zero lower bound.

2002 JUAN S. MORA-SANGUINETTI and RICARDO PÉREZ-VALLS: ¿Cómo afecta la complejidad de la regulación a la demografía empresarial? Evidencia para España.

2003 ALEJANDRO BUESA, FRANCISCO JAVIER POBLACIÓN GARCÍA and JAVIER TARANCÓN: Measuring the procyclicality of impairment accounting regimes: a comparison between IFRS 9 and US GAAP.

2004 HENRIQUE S. BASSO and JUAN F. JIMENO: From secular stagnation to robocalypse? Implications of demographic and technological changes.

2005 LEONARDO GAMBACORTA, SERGIO MAYORDOMO and JOSÉ MARÍA SERENA: Dollar borrowing, firm-characteristics, and FX-hedged funding opportunities.

2006 IRMA ALONSO ÁLVAREZ, VIRGINIA DI NINO and FABRIZIO VENDITTI: Strategic interactions and price dynamics in the global oil market.

2007 JORGE E. GALÁN: The benefits are at the tail: uncovering the impact of macroprudential policy on growth-at-risk.

2008 SVEN BLANK, MATHIAS HOFFMANN and MORITZ A. ROTH: Foreign direct investment and the equity home bias puzzle.

2009 AYMAN EL DAHRAWY SÁNCHEZ-ALBORNOZ and JACOPO TIMINI: Trade agreements and Latin American trade (creation and diversion) and welfare.

2010 ALFREDO GARCÍA-HIERNAUX, MARÍA T. GONZÁLEZ-PÉREZ and DAVID E. GUERRERO: Eurozone prices: a tale of convergence and divergence.

2011 ÁNGEL IVÁN MORENO BERNAL and CARLOS GONZÁLEZ PEDRAZ: Sentiment analysis of the Spanish Financia Stability Report. (There is a Spanish version of this edition with the same number).

2012 MARIAM CAMARERO, MARÍA DOLORES GADEA-RIVAS, ANA GÓMEZ-LOSCOS and CECILIO TAMARIT: External imbalances and recoveries. 
2013 JESÚS FERNÁNDEZ-VILLAVERDE, SAMUEL HURTADO and GALO NUÑO: Financial frictions and the wealth distribution.

2014 RODRIGO BARBONE GONZALEZ, DMITRY KHAMETSHIN, JOSÉ-LUIS PEYDRÓ and ANDREA POLO: Hedger of last resort: evidence from Brazilian FX interventions, local credit, and global financial cycles.

2015 DANILO LEIVA-LEON, GABRIEL PEREZ-QUIROS and EYNO ROTS: Real-time weakness of the global economy: a first assessment of the coronavirus crisis.

2016 JAVIER ANDRÉS, ÓSCAR ARCE, JESÚS FERNÁNDEZ-VILLAVERDE and SAMUEL HURTADO: Deciphering the macroeconomic effects of internal devaluations in a monetary union.

2017 FERNANDO LÓPEZ-VICENTE, JACOPO TIMINI and NICOLA CORTINOVIS: Do trade agreements with labor provisions matter for emerging and developing economies' exports?

2018 EDDIE GERBA and DANILO LEIVA-LEON: Macro-financial interactions in a changing world.

2019 JAIME MARTÍNEZ-MARTÍN and ELENA RUSTICELLI: Keeping track of global trade in real time.

2020 VICTORIA IVASHINA, LUC LAEVEN and ENRIQUE MORAL-BENITO: Loan types and the bank lending channel.

2021 SERGIO MAYORDOMO, NICOLA PAVANINI and EMANUELE TARANTINO: The impact of alternative forms of bank consolidation on credit supply and financial stability.

2022 ALEX ARMAND, PEDRO CARNEIRO, FEDERICO TAGLIATI and YIMING XIA: Can subsidized employment tackle long-term unemployment? Experimental evidence from North Macedonia.

2023 JACOPO TIMINI and FRANCESCA VIANI: A highway across the Atlantic? Trade and welfare effects of the EU-Mercosur agreement.

2024 CORINNA GHIRELLI, JAVIER J. PÉREZ and ALBERTO URTASUN: Economic policy uncertainty in Latin America: measurement using Spanish newspapers and economic spillovers.

2025 MAR DELGADO-TÉLLEZ, ESTHER GORDO, IVÁN KATARYNIUK and JAVIER J. PÉREZ: The decline in public investment: "social dominance" or too-rigid fiscal rules?

2026 ELVIRA PRADES-ILLANES and PATROCINIO TELLO-CASAS: Spanish regions in Global Value Chains: How important? How different?

2027 PABLO AGUILAR, CORINNA GHIRELLI, MATÍAS PACCE and ALBERTO URTASUN: Can news help measure economic sentiment? An application in COVID-19 times.

2028 EDUARDO GUTIÉRREZ, ENRIQUE MORAL-BENITO, DANIEL OTO-PERALÍAS and ROBERTO RAMOS: The spatial distribution of population in Spain: an anomaly in European perspective.

2029 PABLO BURRIEL, CRISTINA CHECHERITA-WESTPHAL, PASCAL JACQUINOT, MATTHIAS SCHÖN and NIKOLAI STÄHLER: Economic consequences of high public debt: evidence from three large scale DSGE models.

2030 BEATRIZ GONZÁLEZ: Macroeconomics, Firm Dynamics and IPOs.

2031 BRINDUSA ANGHEL, NÚRIA RODRÍGUEZ-PLANAS and ANNA SANZ-DE-GALDEANO: Gender Equality and the Math Gender Gap.

2032 ANDRÉS ALONSO and JOSÉ MANUEL CARBÓ: Machine learning in credit risk: measuring the dilemma between prediction and supervisory cost.

2033 PILAR GARCÍA-PEREA, AITOR LACUESTA and PAU ROLDAN-BLANCO: Raising Markups to Survive: Small Spanish Firms during the Great Recession.

2034 MÁXIMO CAMACHO, MATÍAS PACCE and GABRIEL PÉREZ-QUIRÓS: Spillover Effects in International Business Cycles.

\section{BANCODEESPAÑA}

Eurosistema
Unidad de Servicios Generales

Alcalá, 48 - 28014 Madrid

E-mail: publicaciones@bde.es www.bde.es 